This manuscript is a preprint available at EarthArXiv. It has been submitted for publication to Nature Communications and is currently undergoing, but has not yet passed the journal's scientific peer review process. Subsequent versions of this manuscript may therefore have slightly different content. If accepted, the final version of this manuscript will be available via the "Peer-reviewed Publication DOI" on the preprint's EarthArXiv webpage.

Please feel free to contact the corresponding author for comments or further inquiries.

\title{
Climate change induced effects or maldevelopment: small islands and conflicting attribution of root
} causes

\author{
C. Gabriel David ${ }^{1, *}$, Arne Hennig ${ }^{2}$, Beate M. W. Ratter ${ }^{2}$, Volker Roeber ${ }^{3,4}$, Zahid $^{5}$, and \\ Torsten Schlurmann ${ }^{1}$
}

${ }^{1}$ Ludwig-Franzius-Institute for Hydraulics, Estuarine and Coastal Engineering, Leibniz Universität Hannover, Nienburger Straße 4, 30167 Hanover, Germany

${ }^{2}$ Institute for Geography, Department for Earth System Sciences, Universität Hamburg, Bundesstraße 55, 20146

Hamburg, Germany

${ }^{3}$ E2S UPPA, Chair HPC-Waves, SIAME, Université de Pau et des Pays de l'Adour, Allée du parc Montaury, Anglet, France

${ }^{4}$ University of Hawai'i at Mānoa, Department of Oceanography, 1000 Pope Road, Honolulu, HI 96822, USA

${ }^{5}$ formerly Maldives Meteorological Service, Hulhule' 22000, Maldives

*david@lufi.uni-hannover.de

\section{ABSTRACT}

Adapting to sea level rise, climate change, and associated effects is especially challenging in sensitive small-island environments where false adaptation can lead to adverse impacts on natural and societal dynamics. Framing and interest play a decisive role for the successful implementation of any adaptation measures. An interdisciplinary perspective on the interaction of natural dynamics, societal demands, and political decisions is crucial. This study scrutinizes the coastal processes and socio-political dimensions of erosion on the reef island Fuvahmulah, the Maldives. The national government and Fuvahmulah's population have opposed perception and attribution about the cause and effect of the retreating shoreline. To review these perceptions and determine the drivers and processes behind Fuvahmulah's most pressing coastal issue, natural dynamics are recreated with processbased numerical methods and discussed regarding the present and projected sea levels and wave climate. The numerical results are based on high resolution digital elevation models from airborne imagery and in-situ bathymetric measurements. Interviews with national and local actors in coastal development and population surveys complement the physical insights into erosion on the island and scrutinize the socio-political dimension of climate change adaptation on small islands. The results of the interdisciplinary approach demonstrate how small-islands' adaptive capacities are typically impaired in dealing with climate-related changes, they reveal the structural challenges of top-down processes, and disclose the potential of local knowledge to overcome maldevelopment. 


\section{Introduction}

There is high confidence and evidence that climate-change induced sea-level rise increases the risk of small islands to suffer from ocean-borne impacts associated with high tides and swells ${ }^{1-3}$. Small low-lying islands and atolls are especially susceptible to the impacts of sea-level rise, as there is often no higher ground available for the local population to retreat to. In the upcoming decades, stronger and more frequent seaborne hazards will follow global heating, making small islands - in extreme situations - potentially uninhabitable ${ }^{2,4}$. Seaborne hazards on low-lying islands are typically rising sea levels, severe storm surges and swell waves. Likewise, these environmental pressures are constituent parts of the natural dynamics. Coastal environments react to these pressures with a morphodynamic response, for example sediment transport on reef platforms. Therefore, waves, sea level, reef platform, and sediment production are major elements of reef island genesis and evolution ${ }^{5}$.

Due to their geography, small islands' populations are more exposed to marine hazards and more vulnerable than mainland communities. In addition, marine resources are an important factor for island communities, because they provide food and income for the island's inhabitants ${ }^{6}$. But protection from increasing risk of seaborne hazards as well as connection and exploitation of marine resources require concerted development of coastal areas, followed by construction and maintenance of infrastructure. To date, coastal structures and anthropogenic interventions have often resulted in the proliferation of engineering-type hard-coastal protection systems, defending coastal areas up to a certain level of safety from coastal hazards. These interventions are man-made disruptions of the coastal system, often undermining vital ecosystem services and interfering with the morphodynamic interchange on beaches ${ }^{7,8}$. Nevertheless, such structures are implemented widely ${ }^{9}$, even though they interrupt the littoral currents or deteriorate coastal environments to large extents. Anthropogenic interventions in natural dynamics put further pressures on the environment and are driven by political decision-making processes and social interests ${ }^{10}$.

The Intergovernmental Panel on Climate Change (IPCC) names general response strategies to adapt to increased coastal risk and sea level rise in their first assessment report ${ }^{11}$ : protection, accommodation and retreat. In the meantime, further alternatives have emerged and in 2019, the Special Report Ocean and Cryosphere in a Changing Climate (SROCC) of the IPCC complements the response strategies by supporting a broader range of options ${ }^{3}$ : protection, accommodation, advance, retreat, ecosystem-based adaptation, or no response. However, especially small island countries are often confronted with a number of issues that further complicate finding sustainable solutions to infrastructure demands ${ }^{12,13}$ : On the one hand, decisions are regularly made from afar by the central government without addressing the knowledge and integration of local knowledge. On the other hand, island states often lack expertise, human and financial resources to allow thorough planning and proper implementation ${ }^{14}$. Thus, development decisions are embedded in political structures on multiple levels of governance, determining how decisions are made and what actors are involved in the process ${ }^{12,15,16}$.

Against this background, the present study illustrates the problem of interlinked natural and societal dynamics by presenting the case study example of erosion on the reef island Fuvahmulah, the Maldives. The study site is subject to typical aspects of increased disaster risk on small islands in the face of climate change: Fuvahmulah is located in the center of the Indian Ocean, especially exposed to seaborne hazards, such as sea level rise or wave events. In the Indian Ocean, sea level rise is accelerating and the region is prone to experience extreme climate and weather events more frequently ${ }^{17,18}$. The Maldives government is forced to address these challenges and tends to top-down implemented infrastructure projects ${ }^{19}$, which often lead to anthropogenic disturbances in the natural system, thus undermining vital ecosystem services and leading to increased vulnerability ${ }^{7,9}$. In a top-down approach to implement infrastructure projects, decisions on these projects are generally made on a national level and implementation of these projects is prescribed to the local level. However, such top-down prescribed maladaptative practices risk undesirable consequences beyond the connotation of maladaptation to climate change as defined by the IPCC ${ }^{20}$. The IPCC describes maladaptation as action or inaction “... that may lead to increased risk of adverse climate-related outcomes, increased vulnerability to climate change, or diminished welfare, now or in the future" (WGII AR5 ${ }^{21}$, Glossary, page 1769). Within the IPCC's definition of risk as interplay between hazard, vulnerability and exposure, the concept of maladaptation takes both into account: the natural state changes and socio-political context of adverse (in)actions. But analyzing the Maldivian situation disclosed that socio-political 
dynamics leading to human pressures have grown historically within the last decades and, under the current policy pathway, these adverse dynamics will remain to govern changes considerably in the future - besides climate change related pressures ${ }^{13}$. While recent studies found deficient coastal adaptation policies and policy compliance in the Maldives $^{22,23}$, this study scrutinizes the impact of such deficits in practice. It epitomizes maldevelopment and portraits structurally embedded maldevelopment within the socio-political system. In contrast to maladaptation, maldevelopment is not an inadequate adaptation action leading to climate change related risks, but a socio-political phenomenon amplifying maladaptation. Besides the maladaptive impact on nature, maldevelopment emphasizes two socio-political aspects: On the one hand, the societal factors, being the local population's perception of and their attachment to place, their interest in economic development, and environmental protection. On the other hand, the political aspect of responsible authorities, aiming to balance the need for development with environmental protection and issues of sustainability based on decisions and policies. In this sense, maldevelopment is characterized by decisions or policies which are in constant or deliberate favor of inadequate actions and trade-offs towards future climate change related risk.

In that context, this study investigates maladaptive developments and explicates their consequences to facilitate developing adequate and sustainable adaptation strategies - especially in the face of increasing risks due to climate change. This is achieved by an interdisciplinary approach, using methods and results from former studies on natural drivers and responses on small islands ${ }^{24}$ and socio-political framing of climate change adaptation in the Maldives ${ }^{19}$. This study synthesized these results with the Drivers, Pressures, State, Impact and Response model of intervention (DPSIR) and focuses on root causes behind erosion on Fuvahmulah. Following the DPSIR's chain of causal links, the framework facilitates identifying the oceanic-climatic and socio-political pressures leading to state changes of sensitive environments:

After a short introduction to the study site, the result section of this research article scrutinizes the environmental DPSIR constituents "(natural) drivers", "ocean-climate pressures", "state and state changes" as well as their "impact" on nature on Fuvahmulah. The erosion rate is quantified by aerial surveys between 2017 and 2019 and subsequent Structure from Motion - MultiView Stereo (SfM-MVS) post-processing. Based on these topographic and further bathymetric surveys as well as the regional wave climate, two numerical models compute wave-induced currents and sediment transport on Fuvahmulah to reveal the driving natural processes behind erosion. In addition, the study focuses on political and societal (re-)action to pressing coastal issues in the Maldives, addressing the DPSIR constituents "(anthropogenic) drivers", "pressures" and "reactions". Population surveys on the island reveal the perception of inhabitants towards the state of the coastal environment, effects of coastal infrastructure development, as well as the inhabitants' attitudes towards climate change impacts, environmental challenges and their local knowledge of the drivers and processes in sensitive small island environments. The surveys are complemented by interviews with national and local actors involved in coastal management. The interviews examine the decision making process leading to erosion on Fuvahmulah. Erosion is a constant problem to all managed coastlines on the reef islands of the Maldives ${ }^{7,9}$ and the example of Fuvahmulah is no exception: Local erosion on the southeast coast of Fuvahmulah is the most pressing local issue - addressed by the Maldives central government with external funding and consultancy.

The synthesis section combines this study's interdisciplinary insights based on the DPSIR's chain of causal links and discusses the findings of this study in context of maladaptive practices as commonly found on small islands. Synthesizing data of and establishing connections between the DPSIR's constituents facilitates upscaling the lessons learned from this study to other examples of top-down implemented coastal infrastructure in sensitive reef environments. While dealing with coastal infrastructure projects and their impact on the natural environment on Fuvahmulah is an epitome of maldevelopment on small islands, numerous examples exist elsewhere in the Maldives $^{7,9,25}$ and in other Small Island Developing States (SIDS) ${ }^{12,14}$ with similar symptoms of maldevelopment. Also the interdisciplinary collaboration between coastal scientists and human geographers demonstrates how local knowledge of the drivers and processes in sensitive small island environments supports low-regret development and by that mitigates adverse impacts on natural and societal dynamics. 


\section{Study site}

Fuvahmulah is an island in the south of the Maldives, located approximately $30 \mathrm{~km}$ south of the equator (latitude: $-0.30^{\circ}$, longitude: $73.43^{\circ}$, see Fig. 1). Unlike most other inhabited islands of the Maldives, Fuvahmulah is not part of a ring-shaped atoll and lacks the distinct protection features of oceanward islands ${ }^{26}$. Fuvahmulah consists of only one main island and its fringing reef. The main island has a size of about $4.4 \mathrm{~km}$ by $1.0 \mathrm{~km}$ and a coastline of approximately $11 \mathrm{~km}$ length. The island is surrounded by ridges, which are located landward behind the beaches, predominantly vegetated by a fringing palm forest and reach a height of up to about $4 \mathrm{~m}$. These natural barriers mostly protect the island from storm surges, swell waves and help mitigating overwash. Behind these natural coastal protection systems, Fuvahmulah's inland is at mean sea level and hosts two freshwater lakes.

Among islands of the Maldives, the landmark of Fuvahmulah is its sandy beach Thoondu, a coastal spit situated at the north of the island. As wave direction changes with the seasons, Thoondu responds to these changing natural dynamics $^{24}$ : It seasonally adjusts its landform shape, alters its sediment volume and regularly meanders from the northern part of the headland in wet season towards the northeast of the island as well as to the northwestern Geiymiskih beach in the dry season. The constant change of Thoondu is well known by locals and contributes to its uniqueness and the United Nations Educational, Scientific and Cultural Organization (UNESCO) designated Fuvahmulah as a Biosphere reserve in 2020. Any anthropogenic changes into the reef environment or interruption of Thoondu's underlying mechanisms impedes the natural balance behind this natural phenomenon.

The closest neighboring island is Hulhumeedhoo (part of Addu Atoll) lying about $40 \mathrm{~km}$ southwest of Fuvahmulah. The 8510 inhabitants ${ }^{27}$ of Fuvahmulah are exceptionally isolated - even when considering all 26 atolls in the Maldives, stretching over about $870 \mathrm{~km}$ length (north to south) and about $130 \mathrm{~km}$ width (west to east). The isolated location and with the reef and vegetated coastal ridges serve as the only natural coastal protection, Fuvahmulah is particularly susceptible to environmental forcing. Therefore, the island is considered to be highly exposed to wave energy and the southwest monsoon winds ${ }^{28}$.

The isolated position makes Fuvahmulah dependent on transportation infrastructure, which provides a safe connectivity, an access to the outside world, and therefore endows the local economy and supply - especially through the shipping of goods. However, until 2002, Fuvahmulah was only accessible by small fishing boats (dhonis), which had to navigate through the breaking waves over the reef plateau. The dhonis acted as feeders, transporting people, goods, and cargo from Fuvahmulah to larger ships that were waiting offshore. In this procedure, numerous boats capsized and people died. For decades, the people of Fuvahmulah have been requesting the construction of a safe port. The new seaport was constructed on the southeast of the island. The seaport opened in 2002 followed by the construction of an airport for domestic flights in the southwest of the island that opened in 2011.

\section{Results}

\section{Measured coastline erosion on the east side}

Ever since the demanded port has been built, people on the island observe and report severe erosion on the whole eastside of Fuvahmulah ${ }^{29}$. The Digital Elevation Models (DEMs), derived from aerial imagery, prove this observation and quantify the observed erosion rates and the spatial extent along the east coast. Between 2017 and 2019, the cross-sections on the east side north of the seaport show distinct differences in morphologic changes (Fig 2): While the northern area close to Thoondu (Fig 2a) shows a slight increase in beach volume, the other transects depict ongoing erosion (Fig 2b-d). The increase in sediment volume in the north at Thoondu beach is due to the typical dynamic behavior of the northern beaches in response to varying seasonal wave conditions: During dry season, Thoondu beach moves to the northeastern coast ${ }^{24}$. The cross section at the end of Thoondu beach (Fig 2a) shows the calcareous bulk material forming the beach face. When moving further south, the coast of the central east side has a steeper profile than the northern beaches and consists of gravel to cobblestone material (Fig 2b) or larger boulders. The two southernmost transections near the seaport have steep edges, where the mainland meets the reef flat (Fig 2c and 2d). These transections are located about $700 \mathrm{~m}$ (Fig 2c) and $190 \mathrm{~m}$ (Fig 2d) north west of the seaport's entrance. At these locations, the subsurface insular bedrock becomes visible. The erosion process is already noticeable from field observations and has also been widely recognized and reported by locals. 


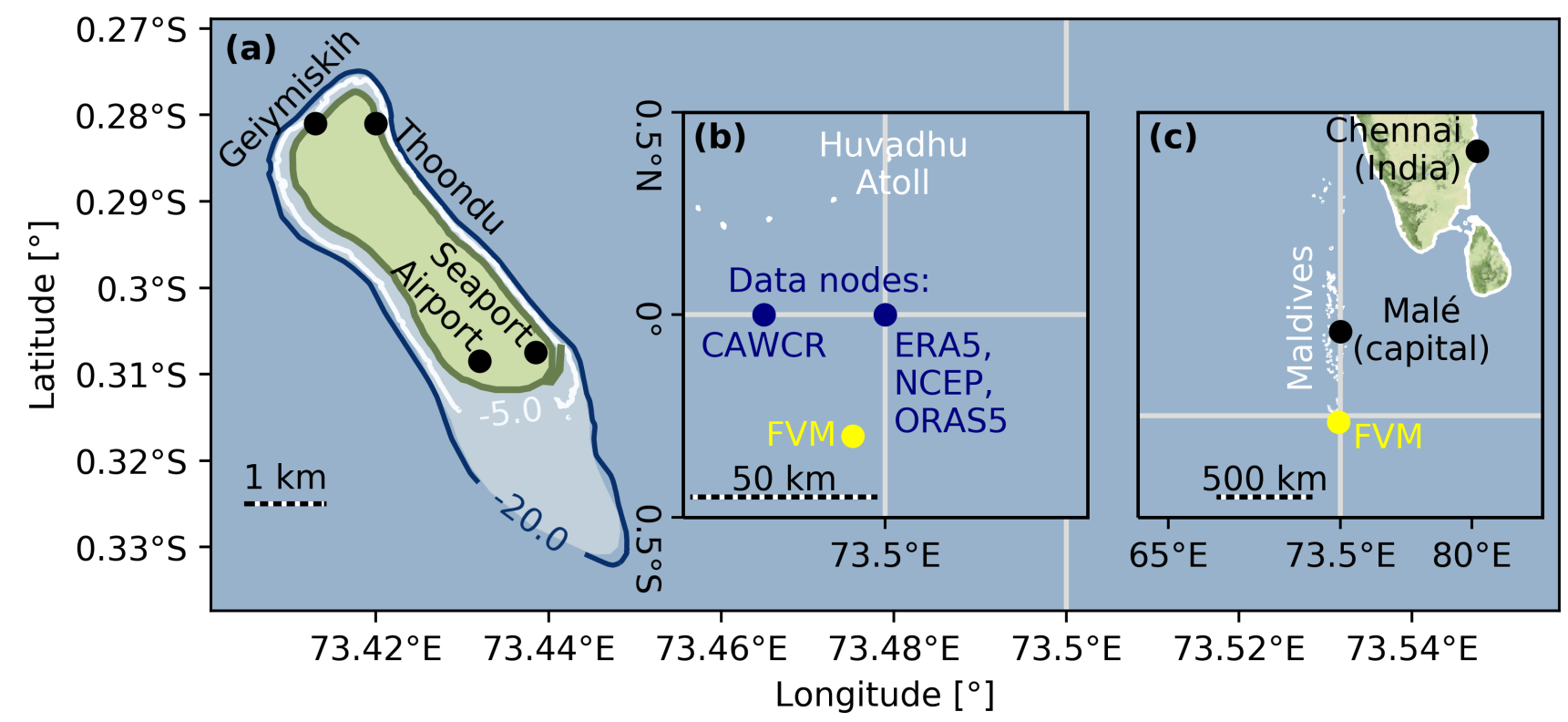

Figure 1. Fuvahmulah (FVM). (a) Shows the island, the seaport, and airport location, as well as the beaches Geiymiskih and Thoondu. Contour lines show the fringing reef depth. (b) Location of Fuvahmulah and data nodes of the hindcast and reanalysis model, from which the wave climate was derived. (c) Location of Fuvahmulah within the Maldives and the Indian Ocean.

Along this stretch of coast further signs of erosion can be identified: Adjacent to the most southern cross-section was a palm tree that later fell onto the reef (see Fig. 3). There are further instances of uprooted trees along the southeastern part of the island. Large parts of Fuvahmulah's coastal ridge have a coastal forest (heylhi), reinforcing the sandy beach profile with its roots. On the east side, waves and currents carve out the sediment under the roots and dislocate broken bedrock material. These observations show that erosion on the east side of Fuvahmulah starts above the reef flat at the bottom of the beach profile. This observation helps to put the transectional erosion into context: While the northern transect shows slight sediment accretion, the central part shows shoreline retreat with maximum values of $0.26 \mathrm{~m}$ to $0.28 \mathrm{~m}$ between 2017 and 2019 (Fig 2d). However, shoreline retreat was only occasionally measurable and not present over the entire central coastline - in contrast to the southeastern coast, adjacent to the port. This area experiences substantial ongoing erosion along its entire coastline in the order of $0.3 \mathrm{~m}$ between 2017 and 2019 with maximum values $\sim 1.33 \mathrm{~m}$ (see Fig. 3). The field data quantifies erosion on the southeast of Fuvahmulah in the order of decimeters over two years. Erosion rates on the east coast decline towards the north. In the north east of Fuvahmulah, the highly dynamic morphology of Thoondu stabilizes the coast. 

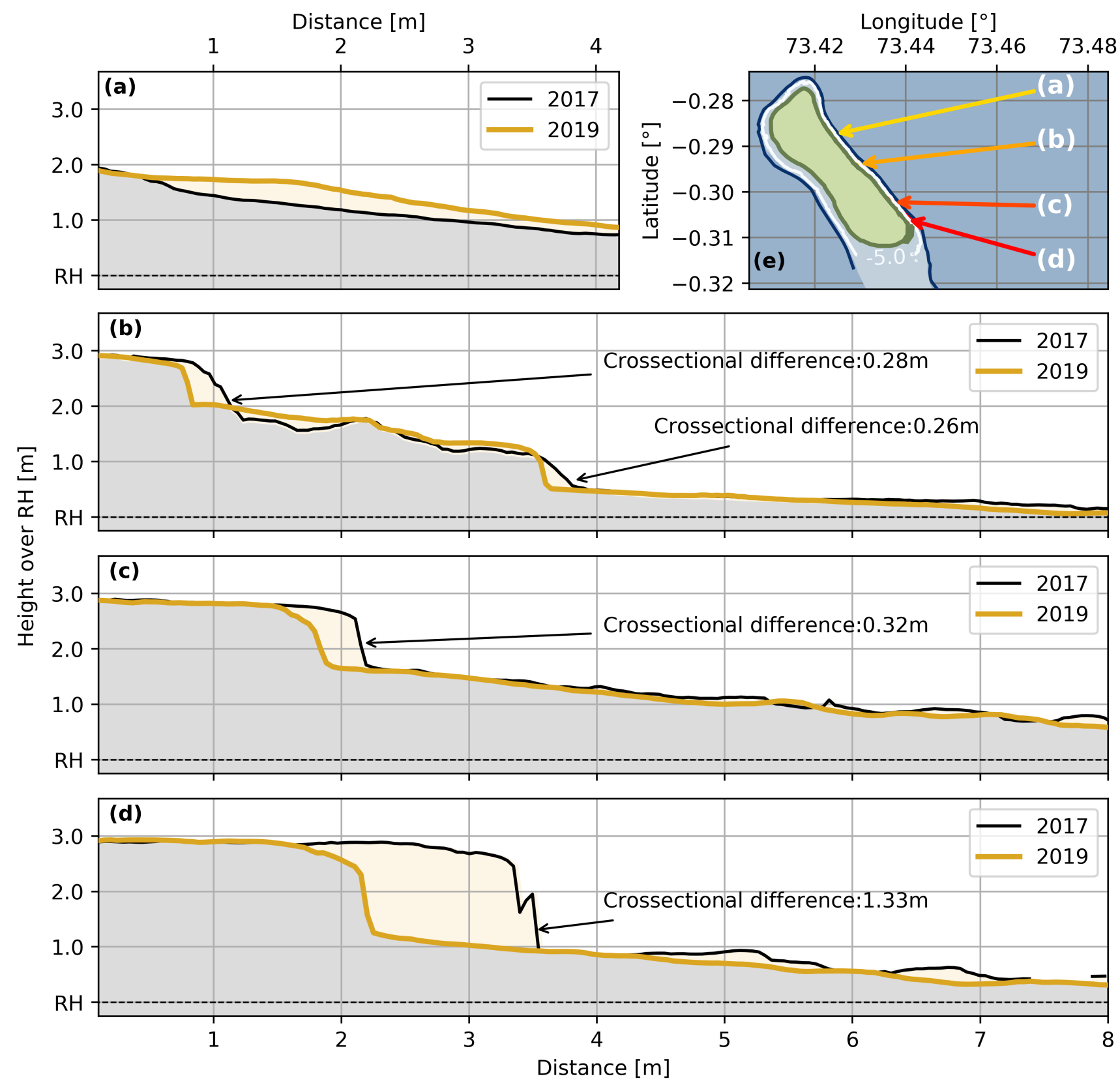

Figure 2. Cross sections of four locations, showing typical coastal profiles along the east side of Fuvahmulah. The profiles originate from the Digital Elevation Models (DEMs) of the dry season of 2017 and 2019. The DEMs were produced by Agisoft Photoscan with the SfM-MVS approach. (a) marks the beginning of the beach Thoondu, showing a slight increase of the sandy beach face. (b) shows a transect from the central area of the east, suffering slight erosion of about $0.26 \mathrm{~m}$ to $0.28 \mathrm{~m}$ at the toe of the beach. Erosion like this can be found in other areas of the central east side but not constantly. (c) and (d) show profiles of the southeastern coast adjacent to the seaport. The steep edge is the transition of the main island into the reef flat. Here the coast suffers constant, structural erosion of about $\sim 0.3 \mathrm{~m}$ with maximum values of $\sim 1.33 \mathrm{~m}$ between 2017 and 2019 (see Fig. 3). 


\begin{tabular}{|l|}
\hline Legend \\
2019 Dry Season DEM [m] \\
-92.0 \\
-89.3 \\
Sediment Budget [m] \\
-2.5 (erosion) \\
-1.25 \\
0 \\
1.25 \\
2.5 (accumulation) \\
\hline
\end{tabular}
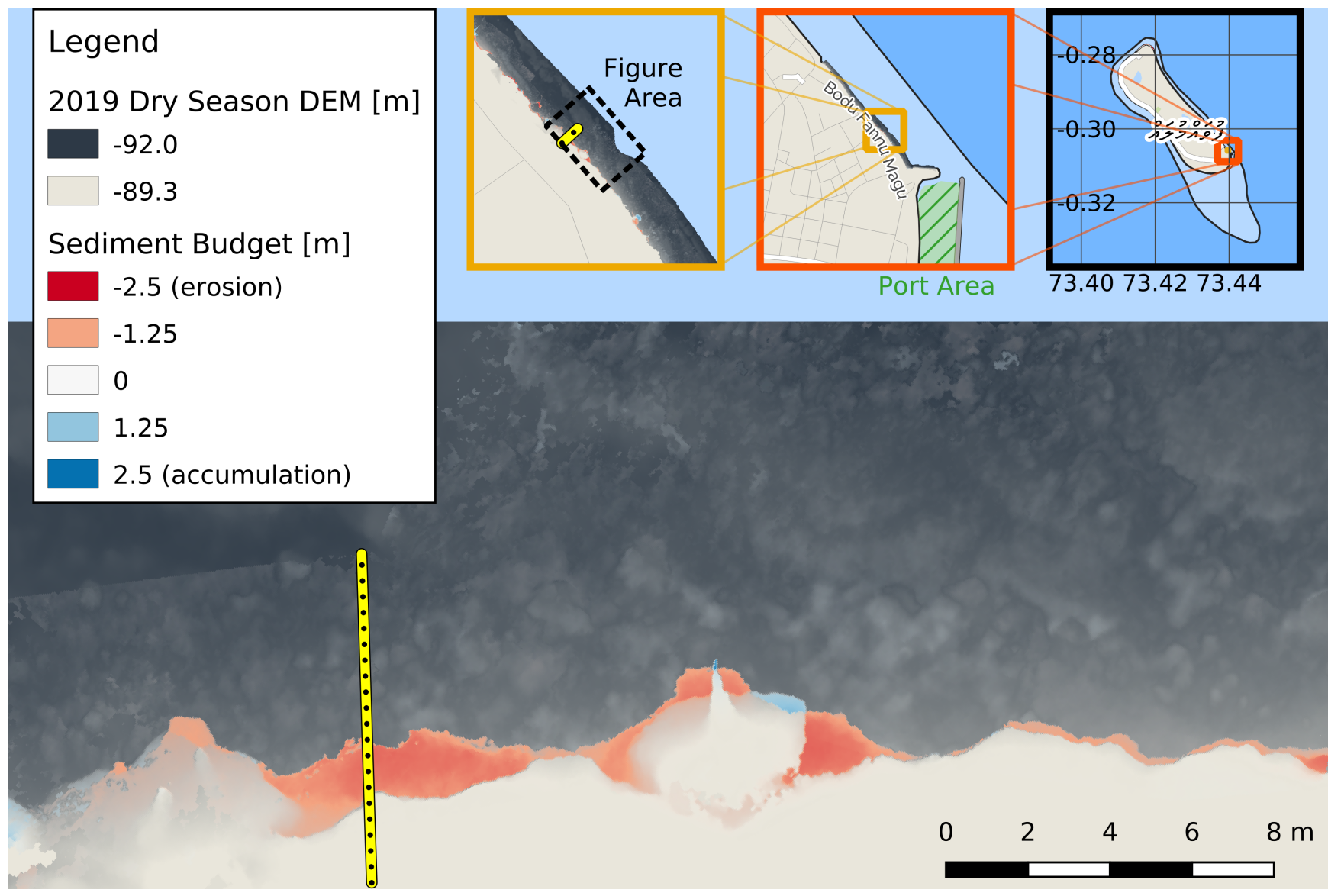

Figure 3. The Digital Elevation Model (DEM) of the dry season 2019 on the southeastern coast of Fuvahmulah, adjacent to the seaport. The figure shows erosion (red) and accumulation (blue) when compared to the DEM of the dry season 2017. The yellow dotted line is the most southern transection of this study with cross-sectional differences of $\sim 1.33 \mathrm{~m}$ (see Fig. $2 \mathrm{~d}$ ). 


\section{Ocean-borne drivers and impacts on the natural physical environment Wave climate of the southern Maldives}

Both, erosion adjacent to the harbor and sediment dynamics on Thoondu beach, are effects of sediment transport dynamics on the reef. The main driver behind sediment transport are wave-induced currents ${ }^{24,30}$. Therefore, the local wave climate and possible changes of the wave climate are of particular importance when assessing shoreline changes. Because measured wave data for the Maldives is scarce, global wave hindcasts or reanalysis models are the only sources containing long-term wave data of directional sea states for the islands of the Maldives. Information on wave data is provided by several meteorological services, such as the National Centers for Environmental Protection (NCEP) of the American National Oceanic and Atmospheric Administration (NOAA), the European Centre for Medium-Range Weather Forecasts (ECMWF) or the Collaboration for Australian Weather and Climate Research (CAWCR) (see Fig. 4a). Annual time series from the considered services agree very well among each other, with mean annual correlation coefficients of $R \geq 0.89$ (Fig 4c). To validate the hindcast and reanalysis data, this study uses harmonized and inter-calibrated Satellite Radar Altimetry (SRA) measurements from the Altimeter Data System (ADS) of the German Research Centre for Geosciences, Helmholtz Centre Potsdam (GFZ) ${ }^{31}$ and compares these to the three data sets considered for this study (Fig 4a). The SRA measurements are available between 1993-04-25 and 2018-06-15. Wave heights from ECMWF's fifth generation atmospheric reanalysis of the global climate (ERA5) data set are closest to the measured SRA wave height in the region of Fuvahmulah. Even though the locations of the CAWCR output nodes differ from the other data sets, analyzing the spatial variation of the CAWCR time series shows a very high correlation of adjacent data nodes $(R \geq 0.977 \pm 0.007$, see Fig. $4 \mathrm{~d})$. The spatial similarity following from this high correlation of wave parameters allows the data sets to be compared among each other despite the spatial distance. Likewise, this shows the wave climate on Fuvahmulah is typical for atolls in the south of the Maldives - as well as the associated exposure and impacts. All further analyses of this study make use of the CAWCR data, because the output node is closest to Fuvahmulah and CAWCR provides significant wave heights under Representative Concentration Pathway (RCP) 4.5, and RCP 8 for the $21^{\text {st }}$ century ${ }^{32}$. These future projections allow this study to scrutinize future states of wave climate on the island as well as their impacts and triggered effects.

The wave climate in the area around Fuvahmulah reflects the dry and wet season both by changed wave heights and wave direction. Median wave heights range between $0.98 \mathrm{~m}$ in March, as well as $1.71 \mathrm{~m}$ in July with a maximum wave height $H_{s, \max }$ of $3.32 \mathrm{~m}$ on June $22^{\text {nd }}, 1987$ (for more statistical data of Fig. 5a and 5f see supplementary materials). This study defines the period between November to February as dry season and the period between April and September as wet season (Fig. 5a). April and October are considered transition months.

The waves are smaller in the dry season and are dominantly approaching the island from SSW $\left(202.5^{\circ}\right.$, see Fig. 5b-e). There are southern and south western portions, but in terms of occurrence they play a minor role. Significant wave heights $H_{s}$ are mostly smaller than $1.7 \mathrm{~m}$ in the dry season (see Fig. 5c). Compared with the dry season, waves approach the island dominantly from southeast and south-southwest in the wet season $\left(135^{\circ}\right.$ and $\left.202.5^{\circ}\right)$. Also, in the rainy season significant wave heights increase and range between $H_{s}=1 \mathrm{~m}-2 \mathrm{~m}$. The Coupled Model Intercomparison Project Phase 5 (CMIP5) data projects future wave heights will not significantly differ under the respective RCPs, considering the reference time frame $1986-2005$ and the last two decades of the $21^{\text {st }}$ century (Fig. 5f, reference time frame according to the fifth assessment report of the IPCC ${ }^{33}$ ). The results are in line with findings of another study using CAWCR wave projection data on a global scale ${ }^{34}$.

As a result, this study scrutinizes waves propagating from SE and SSW into the area, because in both seasons they represent the two dominant shares of the wave rose for Fuvahmulah. Considering today's and future significant wave heights $H_{s}$, the numerical models use the $99^{\text {th }}$ percentile from the reanalysis data set $\left(H_{s, \text { model }}=2.3 \mathrm{~m} \approx\right.$ $\left.H_{s, 99 \%}=2.27 \mathrm{~m}\right)$ as boundary conditions. All conditions are therefore modeled for storm conditions. 


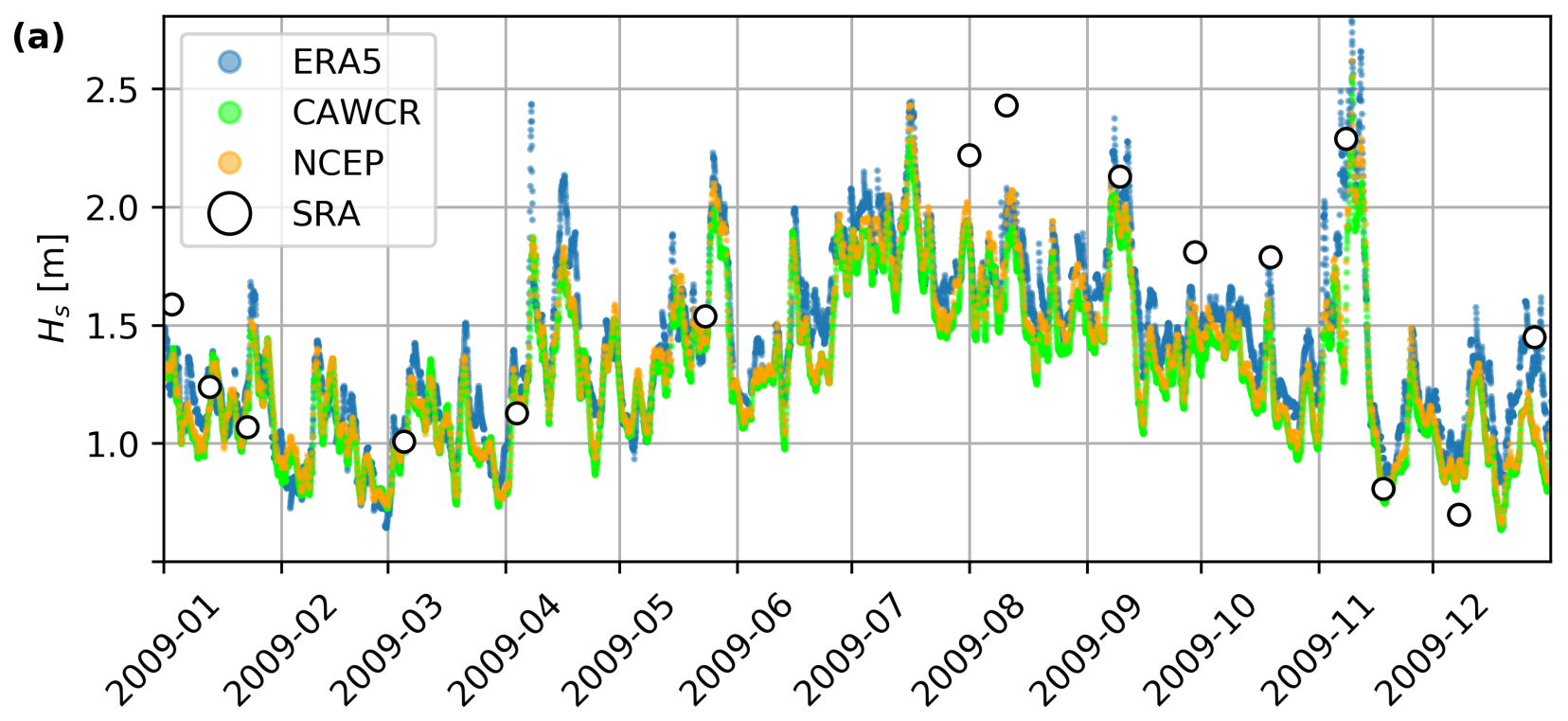

(b)

\begin{tabular}{|l|c|c|c|}
\cline { 2 - 4 } \multicolumn{1}{c|}{} & Mean & Std. Dev & RMSE \\
\hline SRA vs. ERA5 & -0.085 & 0.282 & 0.295 \\
\hline SRA vs. CAWCR & -0.215 & 0.305 & 0.373 \\
\hline SRA vs. NOAA-EMC & -0.154 & 0.311 & 0.347 \\
\hline
\end{tabular}

$$
0.925
$$

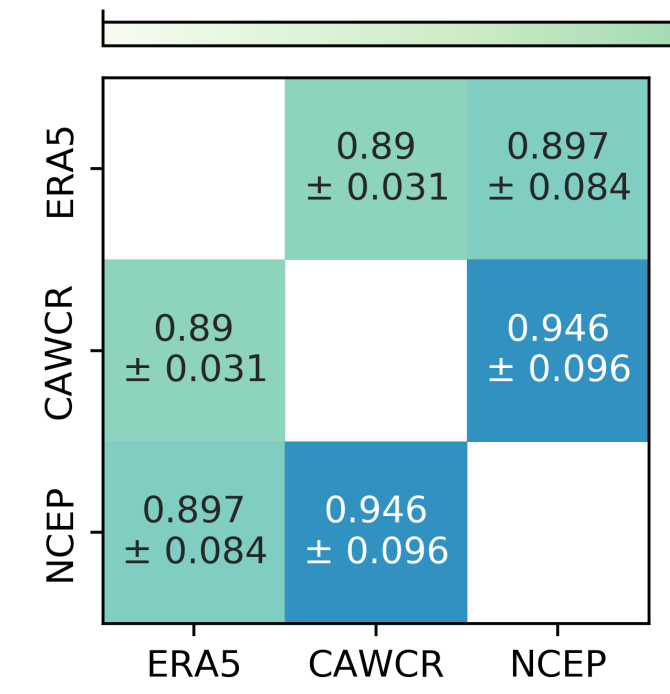

(c) (d)

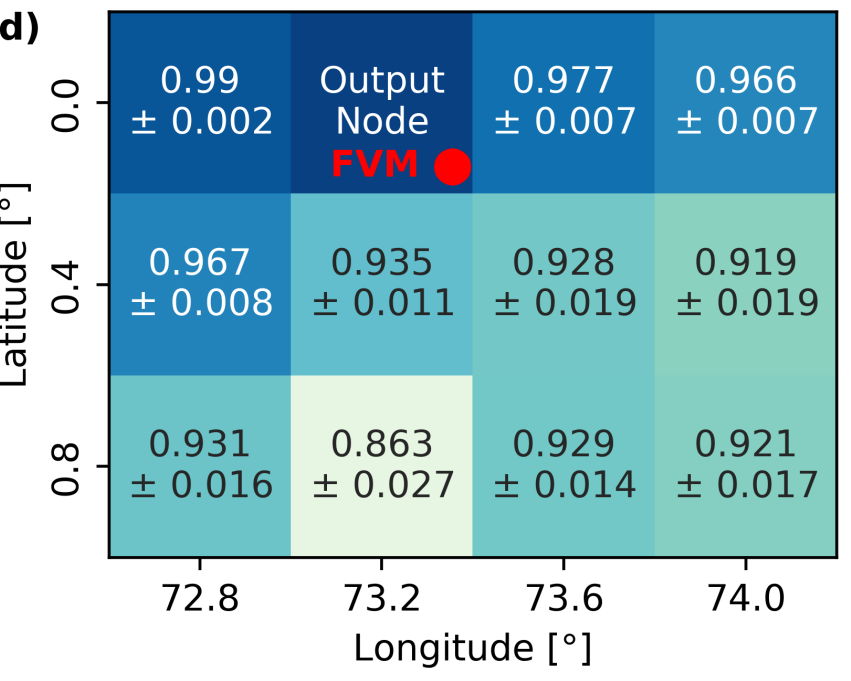

Figure 4. Time series. (a) typical time series of the significant wave height $H_{S}$ for each dataset over one year (here 2009). The white dots are Satellite Radar Altimetry (SRA) measurements of $H_{s}$, recorded in the vicinity of the data output node. (b) shows the deviation between data sets and the SRA measurements (c) cross correlation matrix for $H_{s}$ from each considered data repository between 1980 and 2019-05. (d) spatial cross correlation matrix for data nodes of the CAWCR data set adjacent to the output node considered in this study. The data nodes are in the center of each cell. Values are mean $\mu_{R}$ and standard deviation $\pm \sigma_{R}$ of the correlation coefficient $R$. The red dot marks the location of Fuvahmulah within the matrix. 


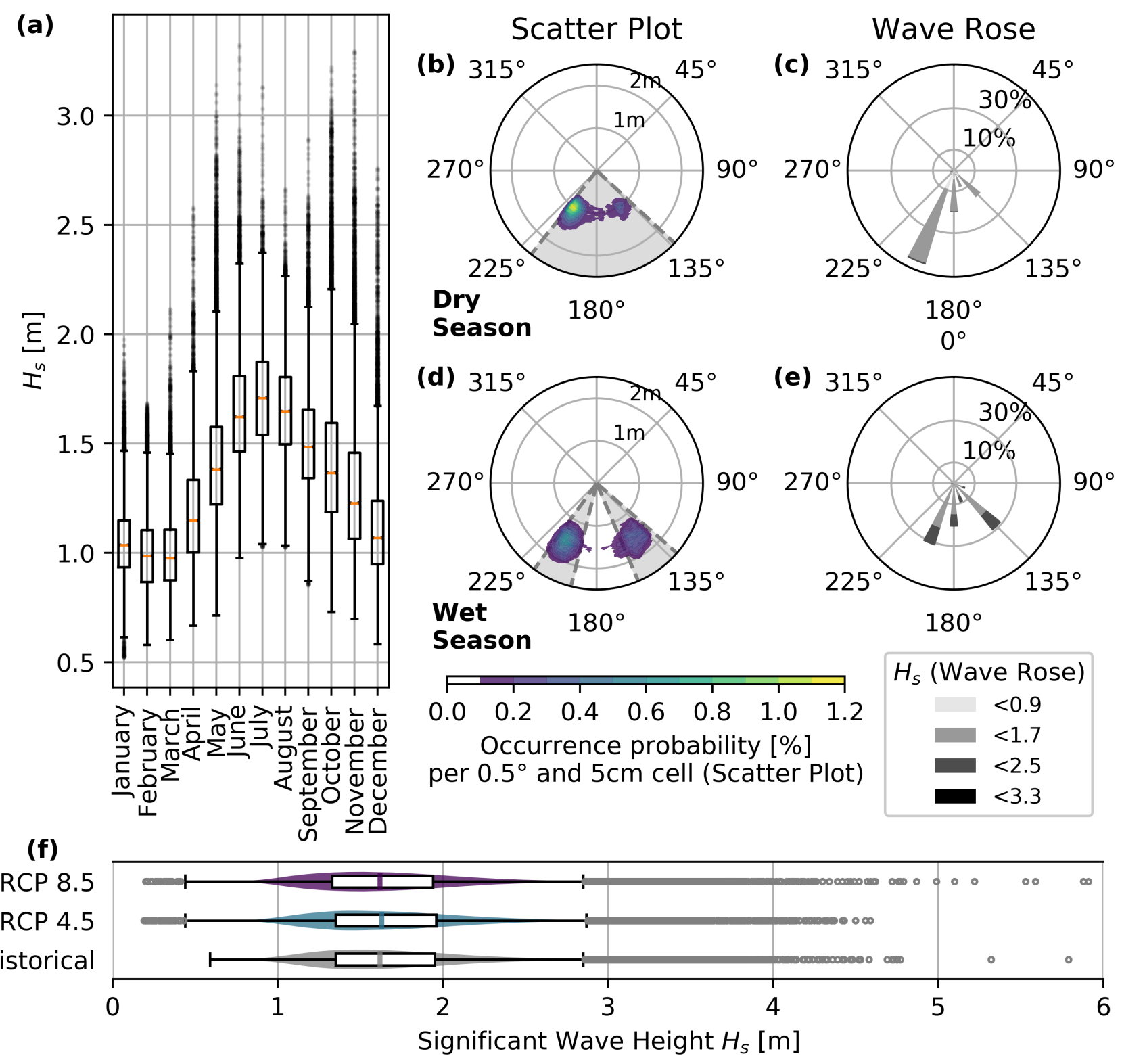

Figure 5. Wave statistics for Fuvahmulah. (a) annual significant wave height distribution for hindcast data between 1980 to 2019 (orange line of the boxplot is the median). (b) shows the discrete marginal distribution between peak wave direction $\theta_{p}$ and significant wave height $H_{s}$ for the dry season, while (d) contains results for the wet season. Here, the colorbar shows the occurrence probability of each $0.5^{\circ}$ wave direction and $0.05 \mathrm{~m}$ wave height cell. The gray areas visualize the significant peak direction range $\theta_{p, r}$ for each subset, containing the directions which combined have the highest $33 \%$ occurrence probability. (c) and (e) show the wave rose for the dry and wet season. (f) are significant wave heights for 2010 - 2019 (Historical) and RCPs 4.5 and 8.5 (median and IQR values for all boxplots in supplementary materials). 

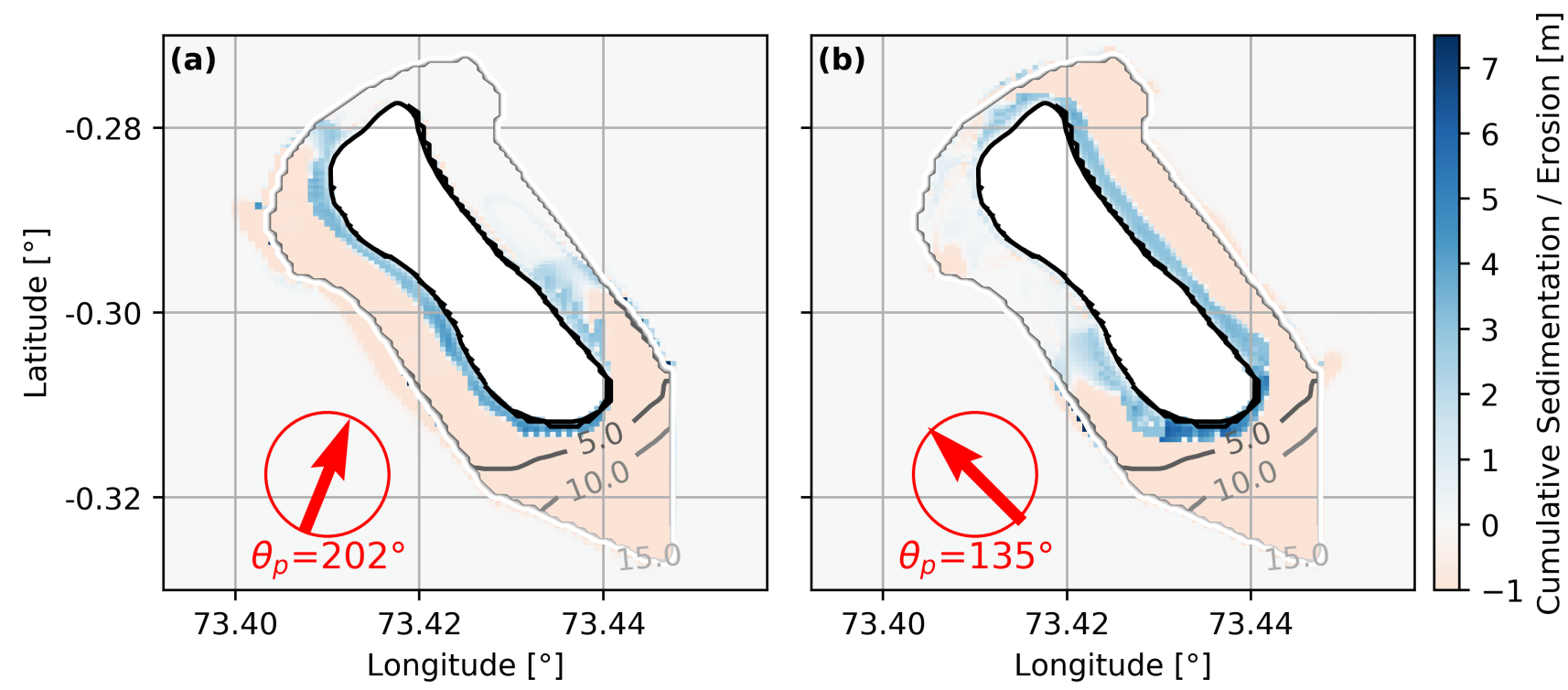

Figure 6. Sediment relocation calculated with D3D for constant waves of one month with significant wave height $H_{s}=2.3 \mathrm{~m}$, peak period $T_{p}=17 \mathrm{~s}$ approaching from (a) $\theta_{p}=202^{\circ}$ and (b) $\theta_{p}=135^{\circ}$. The offshore depth is truncated to $100 \mathrm{~m}$. The idealized reef has a depth of $5 \mathrm{~m}$ to $17.5 \mathrm{~m}$. Gray contour lines mark the water depth on the reef between $5 \mathrm{~m}$ to $15 \mathrm{~m}$ in $5 \mathrm{~m}$ increments. The erodible sediment layer is $1 \mathrm{~m}$ throughout the domain. Sediment accumulation is blue, while erosion is red. The maximum erodible depth is equal to the erodible sediment layer thickness.

\section{Natural morphodynamics on the Fuvahmulah reef platform and the role of anthropogenic interventions}

Results from the wave climate analysis serve as boundary conditions for the regional wave models ${ }^{24}$. The numerical wave models support the observations from DEMs and set these into broader context by considering the wave climate's hydrodynamic forcing. With that, the wave models test the assumption of the harbor infrastructure being the root cause of erosion on the southeast coast, adjacent to seaport. While Delft3D (D3D) calculates the general sediment movement on the Fuvahmulah reef platform for different wave directions, the depth-integrated (2DH) Boussinesq-type wave model gives more detailed information on the role of the port as anthropogenic interference in the natural sediment transport system of the reef. A preceding study gives further insights into the more general dynamic pattern of seasonal and annual sediment transport on the fringing reef of Fuvahmulah ${ }^{24}$.

D3D confirms that the interplay of sediment supply ${ }^{35}$ and wave-induced currents provides sediment for the island (Fig. 6). It further indicates where to expect sediment deposits under the given hydrodynamic forcing. As waves approach from $\theta_{p}=202^{\circ}$, sediment moves towards the island and settles on the west side (Fig. 6a). A smaller sediment depot also forms on the east and southeast of the island under the given premises. Waves from $\theta_{p}=135^{\circ}$ will take sediment from the offshore reef and transport it towards the island (Fig. 6b). The computations for waves from $\theta_{p}=135^{\circ}$ disclose that the sediment stream splits at the southeastern tip of the island, approximately at today's harbor location. The wave-induced currents distribute the sediment along the east coast of the island as well as on the southwest side. A small portion of sediment also moves around the northern tip of the island onto the lee side.

In general, the D3D computations reveal wave-induced currents take sediment from the southern reef and transport it towards the south and east coast without seaport structures present. D3D also indicates the particular importance of the island's southeast part for sediment transport along the entire east coast: Waves from $\theta_{p}=202^{\circ}$ pick up sediment at the southern reef, transport it towards the east coast and the southeast of Fuvahmulah where it finally accumulates. Then, over seasonal cycles, waves from $\theta_{p}=135^{\circ}$ can take away the accumulated sediment and distribute it along the east side.

The 2DH model highlights the difference in wave driven current patterns leading to sediment transport around 
the port area. The models also facilitate scrutinizing the changes in sediment transport with and without the harbor infrastructure being present. These computations confirm the processes projected with D3D and further highlight two factors, contributing to the erosion along the east coast of the island:

The first factor is the available sediment. In both cases - with and without the port structures (breakwater and headland) - waves from $\theta_{p}=202.5^{\circ}$ create a current in front of the port (Fig. 7a and 7b), transporting sediment over the reef. At the same time, in the area of today's harbor entrance, the current decelerates and thus allows for the sediment to accumulate in this area. However, with the breakwater present, the structure interrupts the sediment transport and sediment cannot enter this area. In addition, the breakwater reaches up to the reef's edge. As a consequence, it deflects the current and thus redirects the sediment off the reef into deeper waters.

The second factor is the transport capacity of the east coast's current: Without breakwater, waves from $\theta_{p}=135^{\circ}$ induce a northward current to the area of today's port entrance (see Fig. 7). This is also the area, where sediment was able to settle from the $\theta_{p}=202.5^{\circ}$ component. Instead, with the harbor present, the breakwater obstructs the emerging current in this area and deflects the velocity momentum off-shore. Yet, a wave-induced longshore current is still present along the east coast independently of the port: When waves from $\theta_{p}=135^{\circ}$ approach the reef and break, they induce radiation stresses and subsequently create this longshore current. With missing sediment from the reef, the currents will likely take sediment from the coast, leading to erosion. 

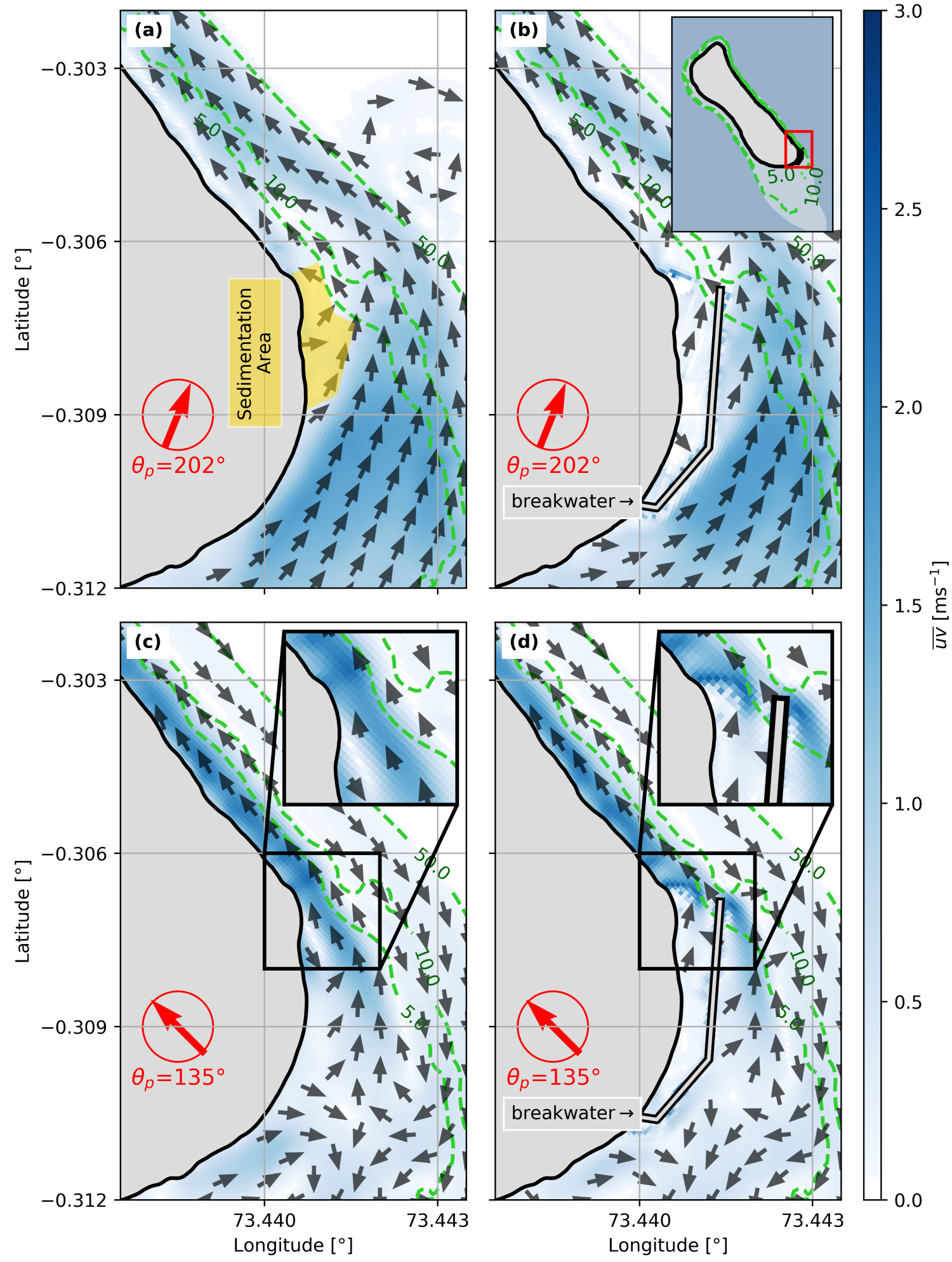

Figure 7. Wave-induced currents $\overline{u v}$ from the $2 \mathrm{DH}$ model for the seaport area in the southeast of Fuvahmulah. The colorbar shows the magnitude of the current between $0.0 \mathrm{~m} \mathrm{~s}^{-1}$ (white) to $3.0 \mathrm{~m} \mathrm{~s}^{-1}$ (blue), while arrows depict the current direction. (a) shows velocity fields from waves with a peak direction of $\theta_{p}=202^{\circ}$ for Fuvahmulah without the harbor, while (b) includes seaport infrastructure. Similarly, (c) shows wave-induced currents before the port construction, while (d) presents today's situation with the harbor present for waves approaching from $\theta_{p}=135^{\circ}$. Green dashed contours show the water depths of the reef platform for $5 \mathrm{~m}, 10 \mathrm{~m}$ and $50 \mathrm{~m}$. 


\section{Governmental and societal framing of coastal development}

On Fuvahmulah $93.8 \%$ of residents are citizens of the Maldives and unlike on other islands of the country, tourism plays a minor role ${ }^{27}$. Fuvahmulah's island dwellers are mainly employed in education and commercial services ${ }^{27}$. Thus, together with the insights of the field campaigns, Fuvahmulah can be considered a local's island. In the household survey, the local community perceives erosion as the most pressing issue (closed question, $27 \%$ of 345 mentions, see supplementary materials). At the same time, both the interviews with government officials as well as the recently issued Environmental Impact Assessments (EIAs) on coastal protection on Fuvahmulah reveal that administrations on both national and local level acknowledge erosion as a high priority issue on the island. But, while there is consensus on the need for action among all interviewed actor groups, attribution of the erosion's root cause varied between the national government representatives and the affected community. On the one hand, the Maldives' dominant adaptation challenge is sea level rise and the associated impacts. In fact, the Maldives national government actively promotes this narrative of being highly vulnerable to climate change induced sea level rise $^{36}$ - even in the case of Fuvahmulah. On the other hand, Fuvahmulah's population is skeptical about the national government's narrative. The household survey contained an open question (without pre-formulated responses) asking the participants to name visible changes of the natural environment on the island. Here, about $36 \%$ of all responses mentioned erosion - and of these, $20 \%$ also attributed the erosion processes on Fuvahmulah specifically to the harbor construction. These diametrically opposed perceptions on root causes behind coastal adaptation originate from the historical context of national politics and local society.

\section{National politic perspective on coastal infrastructure}

First experiences with coastal infrastructure in the Maldives dates back to the 1970s, when the first modern coastal protection constructions were built on the islands ${ }^{25}$. But coastal protection management was not professionalized before 1987 and 1988 when strong coastal floods caused massive damage to the Maldives' capital Male' and on several other islands in the middle of the country (interview with representatives of the Ministry of Environment and Energy (MEE) in 2017). At the same time, establishing coastal protection in the Maldives was accompanied with a rapid increase in population focusing on Male'. In accordance with the Maldives Decentralization Act in 2010, the national government shifted its focus onto regional development centers, equipped with the necessary infrastructure ${ }^{13}$ and limiting the migration to the capital ${ }^{37}$. However, the interviewees still highlight today's accumulation of resources - economic and professional expertise - in the capital Male'. For example, when regarding the implementation of coastal development projects in the Maldives, the planning, implementation and decision-making process are centrally executed and ministerially anchored in the national government without significant involvement of local capacities on the islands. This stands in contrast to the republic's decentralization efforts and the corresponding strengthening of local communities. In the Maldives, actors involved in coastal governance report coastal infrastructure projects, such as seaports as well as coastal protection structures, are predominantly implemented in a top-down process. Such infrastructure projects are usually supported by different international organizations and projects, providing required external financial and knowledge resources. Since 2012, the EIA Regulation of the Maldives requires to assess the (adverse) impact of such infrastructure project on the environment, but quality and compliance to EIA policies - also for example in the tourism sector ${ }^{22}$ - are traditionally weak $^{23}$ and have extensively promulgated technical fortification of many inhabited islands in the Maldives ${ }^{7,9,13}$.

\section{Local society's experience with coastal processes}

In contrast, the traditions and knowledge of Fuvahmulah's inhabitants on their environment as well as experience with coastal hazards led to a different perception on coastal adaptation. More than half of the local respondents feel safe on their island with regard to sea level rise (52\% of the respondents). The interviews have shown this sense of safety roots from the awareness that the lower-lying center of Fuvahmulah is protected from seaborne extreme events by the island's fringing coastal ridges. Locals even believe Fuvahmulah to be comparatively safer than other islands in the Maldives. Some also mention the protective functions of the reef: One respondent answers an open question, asking which elements of the island's natural environment are perceived as important: "Most important is the reef. What I'm saying is that we are protected by the reef. It's not like the [other islands in the Maldives] that are protected by more islands in the atoll" (Survey 1 participant: 080). Others have argued about the protective function of the 
heylhi, which is the natural green belt of vegetation around the entire coastline of Fuvahmulah, stabilizing the shore and protecting local inhabitants from seaborne hazards (see supplementary materials). In addition, building houses was traditionally only allowed in the center of the islands behind the green belt, consisting of local trees and shrubs. However, in 1993, a $86 \mathrm{~m}$ long seawall was built on the central east-side as the first protection measure on the island, followed by noticeable erosion ${ }^{29}$. Today, the seawall is detached from the coast, confirming the earlier findings and a general propensity of adverse impacts of human-made interventions in the coastal environment. While there hasn't been a documented response to the seawall's impact at the time, today's erosion adjacent to Fuvahmulah's seaport is more severe and has a higher impact on the society. For example interviewees of the second survey discussed the effects of erosion as well as the impact on their personal lives, for example: "[...] I am very worried about the soil erosion. I think around 20 feet has gone. So, it is a huge risk for our people in our community. So, I am very much worried about it." (Survey 2 participant: 039). Fuvahmulah has gained more attention by the national government in the last two decades, manifested through numerous development projects in that time, thus erosion - being a high priority issue on the island - is a state affair nowadays.

\section{Coastal adaptation in practice}

In 2014, government actors of the MEE agreed on taking action against erosion adjacent to Fuvahmulah's seaport. They signed a grant arrangement for an internationally sponsored infrastructure development fund and initiated the project "Coastal Protection at Gn. Fuvahmulah, Maldives". This project is defined as "the development, implementation and maintenance of sustainable coastal protection to prevent erosion and flooding on [... ] Fuvahmulah. The main objective of this project is to decrease erosion and flooding through a possible [...] combination of hard and soft coastal engineering interventions [...] to protect the island of Fuvahmulah against flooding due to ongoing coastal erosion and rising sea levels" ${ }^{37}$. An international consultant supported the MEE together with a local sub-contractor in the site investigation, the feasibility study, the technical design ${ }^{37}$ and the draft of the legally mandatory Environmental and Social Impact Assessment (ESIA) ${ }^{38}$.

The technical design report finds human interventions and changes in natural processes disturb the natural balance of the sediment supply along the coastline ${ }^{37}$. According to the report, these human interventions are more specifically the harbor construction, sand mining and earlier reef blasting for beach access, while natural processes disturbing the natural balance are "changes in the natural climate" 37 , but also "may" 37 be a possible deterioration of the coral reef. The report also mentions a lacking local sediment source for the coast and predicts the fringing ridge of Fuvahmulah breaches in the next decades, causing "tremendous flood damage to the island" 37 . Because of this, the report concludes, coastal protection is required and the design should "immediately stop the ongoing erosion" 37 . A preceding feasibility study was cited in the report, identifying two possible solutions against the ongoing erosion and rendering them reasonable while considering their environmental and social impacts - an offshore breakwater and an onshore revetment. The technical report concludes the revetment to be the most viable option, after presenting preliminary designs and a cost-benefit analysis of both alternatives. The final revetment is about to cover approximately the southern $2.6 \mathrm{~km}$ of the $4.0 \mathrm{~km}$ long east side and is designed with a lifetime of 50 years, withstanding hazardous seaborne events with a return period of 100 years.

The ESIA ${ }^{38}$ builds on the technical design report and further underlines the project's significance in the context of future climate change risks, as well as for the national and local economy and finds the project would going to enhance the "sense of security and safety" of Fuvahmulah's island dwellers ${ }^{38}$. The ESIA initially gives five approaches to coastal adaptation, but finds ecological methods would contain a high uncertainty and be ineffective. Also, the report further dismisses soft measures as unsuitable because a proper (local) sediment source is supposedly missing - and finally yields the same alternatives as given by the technical design report ${ }^{37}$. But in addition to the technical design report, the ESIA also contained stakeholder consultations on the project, because in its chapter "project risk mitigation" the ESIA finds "acceptability of the Project by all stakeholders is an important factor for smooth implementation of any project" 38 . The first local stakeholders consultation took place in July 2016 on Fuvahmulah and out of the initially five alternatives only addressed the off-shore and on-shore alternatives. The discussions revealed locals prefer the off-shore alternative, but the ESIA objects as "the risk of affecting [Thoondu] beach was not well understood [by the local stakeholders] at that time”. Therefore, the ESIA mentions another 
consultation with the local government and community in October 2016 "to explain to the stakeholders the preferred alternative that emerged following the feasibility study and proposed in the EIA report".

In principle, public participation is a key component of EIAs ${ }^{22}$ and when taken into the decision making process, it also leads to more sustainable implementation of development projects. But the population survey of this study from March 2017 reveals the unutilised potential to improve the participatory process based on two questions. First, when asking how far politicians work together with the community (open question), $49 \%$ of the survey's respondents found insufficient cooperation of politicians with the community in development projects - while $19 \%$ answer to be sporadically involved and $17 \%$ report to be regularly involved (see supplementary materials). Second, a large majority of $83 \%$ endorses more involvement in the decision-making process regarding the development of the island, while only $15 \%$ of the interviewees do not wish for more participation in this matter. These results disclose an ongoing dissatisfaction of Fuvahmulah's people and the lacking consideration of their interests, opinions, and knowledge - despite or because of insufficient earlier attempts to include their perspective in the ESIA. 


\section{Synthesis \& Discussion}

\section{Maldevelopment adds on top of future risk of climate change}

Small island policy aims for an improved economic situation and at the same time for better provision of access. To improve this situation for the island dwellers of Fuvahmulah, a sea- and an airport were constructed at the time. As of today - almost 20 years later - climate change and sea level rise causes marine pressures and these pressures dominate the discourse on small islands. As a result, small island state governments prepare their nations for the associated adverse impacts. In this sense, coastal erosion is a pressing issue of inhabited reef islands like Fuvahmulah and adaptation measures need to address these issues under deeply uncertain future projections. Following the early example of the capital Male', the centralized government is in favor of generic adaptation measures and implements these measures in a top-down approach ${ }^{13}$. In addition, to realize climate change adaptation and vital development projects, the government of the Maldives - as other SIDS ${ }^{14}$ - most often relies on external, technical knowledge and funding. As a consequence, the resulting planning efforts and constructive responses are mostly based on external design guidelines and building codes. In general, experiences from the past are mainstreamed into international design guidelines and building codes, giving best-practice examples under certain environmental conditions - in case of coastal structures these conditions are those of mainland coasts. Endorsing hard coastal protection is common in SIDS $^{14}$, inheriting both, their top-down governance structure as well as their dependency on international funding, from their colonial legacy. In the Maldives, consequent consideration of hard structures and acceptance of their associated adverse impacts on the environment is historically grown, and ill-prepared policies and policy compliance is projected to continually exist ${ }^{13,23}$. Yet, in both cases, transcribing inappropriate mainland design criteria to sensitive reef environments have caused an insufficient level of coastal protection on small islands in the past. In most cases, there is a straight forward transfer from external knowledge and guidelines to local circumstances, overlooking the special features and services of the fringing coral reef. But corals are important for the livelihood and protection of the accommodated reef islands. In terms of protection, the main ecosystem service of healthy coral reefs is their ability to attenuate waves ${ }^{39}$ and to supply the reef island with coral sediments ${ }^{24,40}$. Generic hard-engineered coastal protection have led to disturbances of natural dynamics and the associated ecosystem services in the Maldives ${ }^{7,9,13,25}$ and in other $\operatorname{SIDS}^{12,41}$. In a worst case scenario such approach to coastal protection and adaptation even fails to alleviate but aggravates adverse effects on the natural environment. Also future plans for coastal protection on the Maldives ${ }^{9}$ fail to implement a local perspective on dealing with changes. Instead, the propensity is to further fortify the island's perimeter with traditional hard-engineered measures ${ }^{13}-$ as in the field case example of Fuvahmulah.

The example of Fuvahmulah epitomizes planning inadequate coastal structures in a reef environment underlies special environmental features and requirements beyond conventional, generic infrastructure design rules and solutions. Traditionally, human intervention beyond the natural green belt of Fuvamulah used to be highly limited, leaving the protection feature and natural sediment distribution on the reef intact. However, the first hard-engineered protection measures have already led to complications ${ }^{29}$. Sand-mining is discussed as a factor and cause for coastal erosion on Fuvahmulah. Sand-mining can potentially put anthropogenic pressure on small islands ${ }^{12}$ and on Fuvahmulah, sand-mining for private purposes was frequently witnessed within the field campaigns around the island. A further reason for increased erosion could be climate variability. However, this study does not include an in-depth assessment on recent climate variability and possible effects on the east-coast of Fuvahmulah. While there are tendencies of changing climate impacts (for example sea surface temperature oscillations in the Indian Ocean) which could have affected the formation of Thoondu beach in $2019^{24}$. The most dominant erosion pattern on Fuvahmulah is distinctively local, adjacent to the seaport in the southeast. Based on the field campaigns and highly resolved data, this study finds coastal erosion on Fuvahmulah to be a negative consequence from the seaport as an anthropogenic intervention into the coral reef system and its natural sediment transport and redistribution pattern much more than sand-mining or climate variability.

Together with today's impact of the seaport, future modifications to the natural reef system will most likely have even more significant adverse effects for greater parts of the coast - especially in spatio-temporal dimensions of the "Coastal Protection at Gn. Fuvahmulah, Maldives". The seaport construction was arguably a trade-off for economic 
development at the expense of natural conservation. However, instead of governing this conflict ${ }^{42}$, future plans are going to respond to erosion associated with the seaport's construction with further generic main-streamed adaptation measures $^{37,38}$ rather than acknowledging and dealing with the root causes of erosion (also being recognized by Fuvahmulah's island dwellers). Concluding from past experiences and findings of this study, these measures fail to address processes of the reef's sediment transport and thus drivers behind erosion faithfully. Such a continuous violation of the reef environment's natural prerequisites and omission of societal demands and preferences for protection will likely lead to additional, cascading pressures to the island. Following the DPSIR chain of causal links this continues affecting the current state adversely and leads to the associated maladaptive impacts on the environment and society. The conventional response to erosion in the Maldives is further rigorous fortification - a common pitfall ultimately undermining the natural dynamics feeding the reef island with coral sediment as epitomized by this study on Fuvahmulah, but scalable to further examples in the Maldives ${ }^{13}$ and on other SIDS ${ }^{14}$.

Scrutinizing the case study of Fuvahmulah with an interdisciplinary approach documents the significance of societal demands and political decisions leading to maladaptation. It shows that maladaptation is implemented in a socio-political context, aiming to improve the economic or societal situation by consistently trading-off ecosystem services. But instead of compensating and mitigating these trade-offs seriously, the socio-political responses lead to cascading maladaptive activities. In the Fuvahmulah example, the constellation of funding source, client and contractor already impedes an unbiased and sincere assessment and thus reaction to the current erosion issue: the project "Coastal Protection at Gn. Fuvahmulah, Maldives" is initiated by the MEE and funded by an infrastructure development facility of an external government. At the same time, the MEE is also consulted by experts of the funding facility's home country. Together with the local subcontractor Maldives Energy and Environmental Company (MEECO), these experts carry out an ESIA, which has to be acknowledged by the MEE - being contracting and supervisory authority at the same time. The subsequent ESIA and technical report dismissed a potential soft solution, such as beach nourishment, claiming no sustainable sediment source was available on the island. However, since the construction of the port, the area west of the seaport and south of the airport host large quantities of deposited sand $^{24}$, which wasn't present prior to the harbor construction (visible on aerial and satellite images in former reports $^{28,29}$ and the EIA ${ }^{38}$ ). The external contractor disregarded the reef as sediment source and sediment transport patterns on reef islands - information made available through research in the past decades ${ }^{5}$ and confirmed to be valid for this island ${ }^{24}$. Such research has emphasized the reef's natural protection capacity and its ability to feed the island in the face of sea level rise. Neglecting these vital ecosystem services and transferring generic solutions for mainland coasts beyond their scope of application is another rigorous example of building in nature - in contrast to a sustainable building with nature ${ }^{43}$. But the technical report and EIA on the coastal protection project discusses only two hard-engineered measures in the stakeholder consultation, while the measure less preferred by locals was finally chosen. By framing stakeholder consultation as project risk mitigation instead of equitable part of decision making, the ESIA epitomizes the deficits of prescribing development projects in a top-down manner and lacks to provide a solution acceptable for the society and suitable for the environment. Somewhat arbitrary compliance with national EIA guidelines is commonplace in the Maldives, leading to questionable assessments regularly ${ }^{23}$ and ultimately failing to address the root causes of adverse impacts on reef environments. Such repeatedly and systematically provoked maladaptive actions go beyond the initial scope of maladaptation. Against this background, this study finds structural maldevelopment being the most important human driver of undesired coastal changes on small islands. Risks evolving from maldevelopment add onto the current and future risks of the other significant natural driver, being climate change and the associated impacts.

\section{Traditional and local knowledge mitigate maldevelopment}

Both the traditional primacy of island development within the borders of the heylhi and veritable attribution of the current coastal erosion reflects that local knowledge helps to identify and overcome local challenges. Analyzing the wave-induced sediment processes in numerical wave models corroborates the local people's assumption that the harbor infrastructure interrupts coastal dynamics and acts as a sediment barrier for the east coast. Local knowledge conveys a distinct local capacity towards economic development in combination with future environmental protection on the island. Implementing and evolving these capacities into a tailored adaptation pathway plan facilitates to 
David, et al. (2020): Climate change induced effects or maldevelopment. This is a non-peer reviewed preprint submitted to EarthArXiv.

consider smaller and less intrusive responses beyond conventional hard-engineering approaches, discloses their potentials and limitations, and leaves further scope of action for the future. Such a more conceptual approach of adaptation pathway planning requires (1) a greater focus on the underlying process, (2) a systematic collaboration between local, national and external experts and stakeholders on the island, (3) ongoing monitoring on the natural and societal impact of the implemented measures, and based on this (4) frequent adjustments on the pathway roadmap by responsible authorities when an adaptation tipping point is reached and the current status, a policy action or actions will fail. In this regard, dynamic adaptive policy models represent suitable, modern methods, allowing more conceptual approaches to be embedded into continuous and sustainable coastal planning ${ }^{44}$. 


\section{Conclusions}

Maldevelopment impairs the adaptive capacities of small islands to deal with climate induced effects and sea level rise impacts. The example of the reef island Fuvahmulah epitomizes local coastal maladaptation in the Maldives, implemented by the national government in a top-down process. Analyzing the natural dynamics of Fuvahmulah's sensitive reef environment reveals the root causes and impacts of anthropogenic interference within the natural reef system. But this study's interdisciplinary approach also scrutinizes the socio-political dimensions of these findings: Analyzing differing interests and viewpoints discloses the structural barriers of top-down development initiatives for climate change adaptation on small islands. In addition, this approach also exhibits the potential of local knowledge and capacities to prevent or overcome maldevelopment.

The highly resolved areal SfM-MVS measurements of Fuvahmulah's coast quantify ongoing coastal erosion on the lower east-side of the islands, adjacent to the harbor. A seaport was long demanded by the inhabitants of Fuvahmulah, improving safe operation on boats and protection from waves. The regional wave climate also governs the local sediment transport processes on the reef. Incorporating the topographic and reef measurements as well as the wave climate in numerical wave models helps to scrutinize the root cause behind the measured erosion on Fuvahmulah's east coast: The seaport intervenes with the natural sediment transport and acts as barrier, deflecting suspended sediment off the reef, which otherwise would have been transported along the east side and constantly nourished the coast.

The perception analysis and population surveys on Fuvahmulah revealed that island dwellers are well aware of the port's impacts and are doubting the national government's narrative, framing coastal erosion as climate change and sea level rise impact. This alone has far-reaching effects on national climate policy and the willingness of the population to implement it. Recent infrastructure projects on Fuvahmulah were supported by international donors and consultants, addressing local development and adaptation issues with external generic solutions. But these solutions neither regarded the capacities of the reef system, nor integrated local knowledge to avoid or mitigate coastal issues, but instead added to the existing and increasing ocean-climate pressures on Fuvahmulah.

Amalgamating coastal and societal aspects resulted in a comprehensive understanding of the ongoing natural and socio-political processes behind coastal issues. These interdisciplinary insights underline that adaptation strategies and measures need to be adjusted to local circumstances and by that avoid an interruption of the coastal system, undermining vital ecosystem services and sustaining natural coastal protection.

Structural maldevelopment to date impairs the potential of dealing with further future changes, such as sea level rise, extreme wave events, and storm surges. Studying maldevelopment in its comprehensiveness leads to the conclusion that sustainable development requires an integrated analysis of political interests and societal demands within the natural boundaries, in order to adequately address future climate change stressors. This is very likely not only true for Fuvahmulah, as many small islands in the Maldives and in the world show symptoms of maldevelopment. 


\section{Methods}

\section{Digital elevation model (DEM)}

Based on three field campaigns, Unmanned Aerial Vehicles (UAVs) capture the topography of Fuvahmulah and facilitate analyzing shoreline changes. A DJI Phantom 4 multicopter recorded aerial photos within two field campaigns in March and September 2017. A DJI Phantom 4 Pro was used for the coastal survey in March 2019. The aerial surveys covered the entire coast of Fuvahmulah, except the beaches adjacent to the airport, which are a no-flight-zone. After recording the aerial images of Fuvahmulah's coast, Agisoft Photoscan Pro (version 1.4.5 build 7354) processes the photos into DEMs by means of SfM-MVS ${ }^{45}$. DEMs are three dimensional models of the area, containing height and color information, here in about $3.5 \mathrm{~cm} \mathrm{px}^{-1}$ resolution. The resulting coastal DEMs recorded at different points in time, facilitate analyzing changes of sediment volumes on the beach, shoreline location and vegetation. The general workflow in Photoscan is to align the photos, georeference the model with Ground Control Points (GCPs), and create a dense point cloud as well as a mesh of the area. Photoscan derives the DEM from the dense point cloud, while the mesh serves as base for the orthophoto (for further information on input parameters of each processing step in Photoscan, see Supplementary Materials). To position the models in the World Geodetic System (WGS84), the March 2019 DEM uses a unique set of GCPs around the island. The 2017 model uses the drone's Global Navigation Satellite System (GNSS) antennas for initial positioning. Afterwards virtual Ground Control Points (vGCPs) of specific landmarks available in both models georeference the 2017 DEMs with the 2019 DEMs.

In general, the inspected erosion starts at the bottom of the beach profile. Waves and currents carve out the sediment under the roots of the coastal forest or dislocate coral rocks. Due to the specific erosion process on Fuvahmulah, early erosion remains mostly undetected in the DEMs, mostly until the upper part slips or collapses. However, adjacent to the seaport, the erosion is advanced enough to be visible in the DEMs.

\section{Hydrodynamic boundary conditions}

To evaluate the drivers behind sediment transport, this study uses numerical near-shore wave models. These models require regional wave climate information as hydrodynamic boundary conditions. To derive the wave climate for Fuvahmulah, this study considers data from three global hindcast and reanalysis models from the Collaboration for Australian Weather and Climate Research (CAWCR), National Centers for Environmental Protection (NCEP) of the American National Oceanic and Atmospheric Administration (NOAA), and European Centre for Medium-Range Weather Forecasts (ECMWF) (see Tab. 1). Data from wave spectra are an appropriate resource to be used as boundary condition in models of finer spatio-temporal resolution ${ }^{46,47}$. To validate the modeled wave climate data, this study compares each data set with wave heights derived from individual harmonized and inter-calibrated SRA measurements of the GFZ Altimeter Data System ${ }^{31}$ (see Fig. 4a). The SRA data is taken from latitude $0^{\circ}$ and longitude $73^{\circ}$ in a radius of $1.5 \mathrm{~km}$ between 1993-04-25 and 2018-06-15.

The CAWCR provides hindcast wave data ${ }^{48}$ generated with the WAVEWATCH III ocean wave model ${ }^{49}$. The closest output node to Fuvahmulah and the SRA data from GFZ is at $0.0^{\circ}$ latitude, $73.2^{\circ}$ longitude. The model uses a grid with $0.4^{\circ}$ zonal and meridional wide increments. CAWCR also provides estimates for wave heights under different RCP in the $21^{\text {st }}$ century. WAVEWATCH III is a numerical model calculating wind wave generation and wave propagation based on the random phase action density balance equation for wave spectra ${ }^{49}$. The waves are forced by surface wind fields from atmospheric models ${ }^{50}$, made available by the NCEP as Climate Forecast System Reanalysis (CFSR) and Climate Forecast System Reanalysis v.2 (CFSv2). The Environmental Modeling Center (EMC) of NCEP runs an own hindcast with WAVEWATCH III and their bias corrected wind forcing. EMC maintains WAVEWATCH III and places the code at disposal. WAVEWATCH III is a fork of the ocean wave model $\left(W_{A M}^{51}\right)$. The ECMWF uses the WAM model for their ERA5 with wind forcing from their Integrated Forecasting System (IFS) ${ }^{52}$. The data is available through the Copernicus Climate Change Service $(\mathrm{C} 3 \mathrm{~S})^{53}$. The closest data node to Fuvahmulah for both NCEP and ECMWF's ERA5 are at $0.0^{\circ}$ latitude, $73.5^{\circ}$ longitude (see Fig. 1), while the comparison with the SRA data from GFZ were taken from the node at $0.0^{\circ}$ latitude, $73.0^{\circ}$ longitude. Tab. 1 juxtaposes the underlying models, key input parameters and output variables of each data set for this study. 
Table 1. Comparison of the considered data repositories

CAWCR

\begin{tabular}{|c|c|c|c|}
\hline Designation & Hindcast & Hindcast & Hindcast \\
\hline Time series & 1979-2010 & $2011-01$ to $2013-05$ & 2013-06 to present \\
\hline Wave model & \multicolumn{2}{|c|}{ WAVEWATCH III v4.08 } & WAVEWATCH III v4.18 \\
\hline Wind forcing & $\begin{array}{l}\text { NCEP CFSR hourly } \\
\text { winds (Reanalysis) }\end{array}$ & $\begin{array}{l}\text { NCEP CFSv2 hourly } \\
\text { winds (Reanalysis) }\end{array}$ & $\begin{array}{l}\text { NCEP CFSv2 hourly } \\
\text { winds (Reanalysis) }\end{array}$ \\
\hline Grid resolution & $0.4^{\circ}\left(24^{\prime}\right)$ & $0.4^{\circ}\left(24^{\prime}\right)$ & $0.4^{\circ}\left(24^{\prime}\right)$ \\
\hline Temporal resolution & Hourly & Hourly & Hourly \\
\hline Spectral output & 3683 points & 3683 points & 3683 points \\
\hline Initializing Phase & 1979-01 & - & - \\
\hline Partitions & 4 & 4 & 4 \\
\hline Citation & $\mathrm{CAWCR}^{48}$ & $\mathrm{CAWCR}^{48}$ & $\mathrm{CAWCR}^{48}$ \\
\hline \multirow[t]{2}{*}{ Extra } & \multicolumn{3}{|c|}{ RCP 3.5, RCP 4.5 and RCP 8.5 forecast $^{54}$} \\
\hline & \multicolumn{3}{|c|}{ Nested Australian and Western Pacific subgrids } \\
\hline
\end{tabular}

NCEP-EMC

\begin{tabular}{|c|c|c|c|}
\hline Designation & Hindcast (Phase 2) & Production Hindcast & Reanalysis \\
\hline Time series & 1979 to 2009 & $2009-02$ to $2019-05$ & 1979 to present \\
\hline Wave model & \multicolumn{2}{|c|}{ WAVEWATCH III v5.08 } & WAM $^{1}$ \\
\hline Wind forcing & $\begin{array}{l}\text { NCEP CFSR hourly } \\
\text { winds (Reanalysis) }\end{array}$ & $\begin{array}{l}\text { NCEP GFS } 6 \mathrm{~h} \text { winds } \\
\text { (Forecast) }\end{array}$ & $\begin{array}{l}\text { IFS atmospheric model } \\
\text { (CY41R2) }\end{array}$ \\
\hline Grid resolution & $0.5^{\circ}\left(30^{\prime}\right)$ & $0.5^{\circ}\left(30^{\prime}\right)$ & $0.5^{\circ}\left(30^{\prime}\right)$ \\
\hline Temporal resolution & 3 Hours & 3 Hours & Hourly single levels \\
\hline Spectral output & 2D at each node & $>2000$ points & 2D at each node \\
\hline Initializing Phase & until 1979-01-04 & - & - \\
\hline Partitions & 23 & 23 & 3 \\
\hline Citation & NCEP-EMC homepage ${ }^{2}$ & NCEP-EMC homepage $^{2}$ & C3S Climate Data Store ${ }^{3}$ \\
\hline Extra & $\begin{array}{l}\text { Arctic Ocean and } 13 \\
\text { nested subgrids }\end{array}$ & $\begin{array}{l}\text { Arctic Ocean and } 7 \\
\text { nested subgrids }\end{array}$ & $\begin{array}{l}\text { 4D VAR data assimila- } \\
\text { tion }\end{array}$ \\
\hline
\end{tabular}

${ }^{1}$ adapted by ECMWF within the IFS CY41R2 $2^{52}$

2 polar.ncep.noaa.gov/waves/hindcasts/, last accessed 2020-03-22

${ }^{3}$ see ERA5 ${ }^{53}$

To compare the data sets, this study correlates ocean wave time series from all three repositories with a crosscorrelation function from the nodes closest to Fuvahmulah. The general solution for a cross-correlation function writes as:

$$
C_{A B}(\tau)=\frac{1}{N-m} \sum_{N=0}^{N-m}\left(A(m \Delta t)-\mu_{A}\right)\left(B(m \Delta t+\tau)-\mu_{B}\right)
$$

with $\tau=m \Delta t$ as the lag time for $m$ sampling time increments and $N$ the number of values in the correlated time series $A$ and $B$, which are reduced by their respective means $\mu_{A}$ and $\mu_{B}$. The normalized cross-correlation follows from considering the standard deviations $\sigma_{A}$ and $\sigma_{B}$ of each time series as

$$
\rho_{A B}(\tau)=\frac{C_{A B}(\tau)}{\sigma_{A}(\tau) \sigma_{B}(\tau)}
$$


The normalized cross-correlation values range from 1 for equal signals over 0 for uncorrelated signals to -1 as a reverse or negatively correlated signal. The corresponding lag time $\tau$ of the highest absolute value, here the correlation coefficient $R$ of the cross-correlation, gives information about the time-shift between both signals.

The wave data in each repository contains time series of over 40 years. For the analysis, the time series is split up in annual sections from 1980 until 2019-05 and used separately in the cross-correlation function (Fig 4b), resulting in 39 annual cross correlation coefficients. When correlating the hourly data of CAWCR and ERA5 with the 3-hourly NCEP time series, the hourly time series were reduced to the associated 3-hourly values of the NCEP time series. To estimate the spatial variability of the data, a correlation of different spatial output nodes of the CAWCR data set (Fig 4c) uses the entire CAWCR time series from 1979 to 2019.

This study further evaluates the impact of climate change on the wave climate according to the baseline chosen in the IPCC's fifth assessment report ${ }^{33}$ by comparing the mean significant wave heights between the time periods 1986 - 2005 and 2081 - 2100 (end of the century) under RCP 4.5 and RCP 8.5 projections. These projections are part of the CAWCR repositories ${ }^{54}$. The data is computed with the same tools as the hindcast data. However, the global grid is coarser with spatial increments of $1.0^{\circ}\left(60^{\prime}\right)$ and a temporal resolution of 6 hours. The RCP 4.5 and RCP 8.5 computations for wind waves use surface wind projections of 8 atmospheric models ${ }^{54}$.

Because the CAWCR data set has the output node closest to Fuvahmulah, boundary conditions for the numerical models used in this study were derived from the CAWCR data node northwest of the island at $0.0^{\circ}$ latitude, $73.2^{\circ}$ longitude (see Fig. 1). The boundary conditions come from the entire, available hindcast data of significant wave heights $H_{s}$ and associated peak directions $\theta_{p}$ between 1979 to 2020-02. The analysis of peak directions $\theta_{p}$ for each season introduces the range of peak directions $\theta_{p, r}$. This range comes from a discrete probability distribution of the entire time-series and contains the directions, which combined have the highest $33 \%$ occurrence probability (see Fig. 5).

In general, the performance of global ocean wave models is good in the Indian Ocean when compared to buoy data ${ }^{47,55}$. The comparison to SRA measurements shows that wave data from global models occasionally underestimates wave heights, due to their relatively coarse spatio-temporal resolution in order of kilometers and hours. This improves with higher spatio-temporal resolutions ${ }^{56}$. Other studies have shown that underpredicted wave heights are especially prominent in extreme events ${ }^{57}$. In addition, non-linear effects can mitigate increased flood risk associated with sea-level rise ${ }^{58}$. Since 1992 and in contrast to sea-level rise, wave heights have only increased by about 0 to $\sim 1 \mathrm{~cm} \mathrm{yr}^{-1}$ for the Maldives according to a most recent study ${ }^{59}$ (see also Fig. $5 f$ ). In front of this background, wave heights under the respective RCP scenarios are conservative estimates of hazard levels, as the ocean wave models have a resolution of $1.0^{\circ}$ and 6 hour time steps versus $0.4^{\circ}$ to $0.5^{\circ}$ spatial and hourly or 3 hour temporal resolution for the hindcast models. However, even when (1) combining today's wave heights with a projected sea level rise of about $0.4 \mathrm{~m}$ to $0.8 \mathrm{~m}$ and (2) comparing it against the topographic height of Fuvahmulah with $\sim 3.5 \mathrm{~m}$ above sea level, both factors will lead to more frequent extreme events. In this context, on Fuvahmulah, historically rare extreme events will become common by 2100 under all $\mathrm{RCPs}^{2,3}$.

\section{Numerical wave models}

With the wave climate as boundary conditions, numerical wave models can reconstruct waves and wave-induced currents and thus sediment transport processes on the reef under different scenarios (for example with or without seaport infrastructure). This study uses two numerical models for different purposes. First, D3D helps to study the general sediment transport processes on the fringing reef platform under the characteristic wave climate of the region. The phase-averaging wave module of D3D uses wave spectra in its governing equations and combines them with sediment transport formulations ${ }^{60}$. To study the influence of the port infrastructure on the adjacent coastal areas, this study uses the depth-integrated (2DH) Boussinesq-type model BOSZ ${ }^{46}$. The phase-resolving wave model can directly capture wave transformation and secondary processes such as wave setup and recirculation over the reef. It is therefore suitable to study the current-induced processes in the study area in detail. While the computation of direct sediment transportation is challenging, the general wave-induced current velocities or shear stresses from wave-induced currents serve as the driving forces behind the most prominent bedload and suspended sediment transportation formulations ${ }^{60}$. Thus, acceleration, deceleration and presence of current fields are direct indicators for 
sediment accretion and sediment pick-up.

D3D has been used successfully for calculating sediment transport and demonstrated good performance in both experimental and hindcast studies ${ }^{61}$. The model is in general capable to outline the morphodynamic processes on the Fuvahmulah reef. To remain numerically stable and efficient in terms of computational resources, the settings in this study contain the following simplifications: The model uses a relatively coarse rectilinear grid off-shore, with a refined resolution of $\Delta x=67 \mathrm{~m}, \Delta y=15 \mathrm{~m}$ around Fuvahmulah. To study the morphodynamic processes around the island, D3D uses both the WAVE and the FLOW module. The reef depth and island height are based on topographic and bathymetric surveys within the field campaigns, however the implementation in D3D is idealized: The off-shore section has a constant water depth of $h=100 \mathrm{~m}$. The fringing reef has a constant depth of $h=4 \mathrm{~m}$ which increases on the southern reef platform to $h=17.5 \mathrm{~m}$. The island Fuvahmulah lies at $3 \mathrm{~m}$ above Mean Sea Level (MSL). The off-shore reef south of the island has a similar shape in the model compared to the real reef. However, to provide enough cells to transport sediment, the virtual fringing reef in the model is wider than the physical reef around Fuvahmulah. To evaluate sediment transport pathways around the island, the reef was covered with a $1 \mathrm{~m}$ layer of erodible sediment at the start of each computation. The underlying assumption is that the reef platform is the main sediment supplier for the island ${ }^{24,35}$. While the simplifications allow for a larger set of computations, the implementation is still sufficiently detailed to capture the very general interaction between bathymetry, waves and sediment on the reef.

The following simulations in D3D use a PM-spectrum with $H_{s}=2.3 \mathrm{~m}, T_{p}=17 \mathrm{~s}$ and a peak direction of $\theta_{p}=202.5^{\circ}$ and $\theta_{p}=135^{\circ}$ respectively. Despite the complexity of sediment transport on coral reefs ${ }^{62}$, for a first estimation, D3D runs only with the default (suspended and bed-load) sediment transport formulations ${ }^{60}$. All simulations use the same sediment properties: The sediment layer thickness is $d_{\text {sed }}=1 \mathrm{~m}$, sediment density is $\rho_{\text {sed }}=2.0 \mathrm{~g} \mathrm{~cm}^{-3}$ (based on in-situ measurements) and sediment grain size (diameter) is $D=200 \mu \mathrm{m}$. The morphological scale factor is $f_{M O R}=2$.

The reef bathymetry in the 2DH model comes from records of a single-beam, dual-frequency echo-sounder (Dr. Fahrentholz LituBox 15/200) taken during the first field campaign in 2017. The echo-sounder was able to show water depths up to $\sim 80-100 \mathrm{~m}$. However, as water depths increase rapidly beyond the reef plateau, records from the echo-sounder exceeding the maximum depth of the Fuvahmulah reef plateau at the southern tip of $\sim 20-25 \mathrm{~m}$ were discarded. The minimum depth of the echo-sounder was $4 \mathrm{~m}$ due to the draft of the boat. The 2017 Photoscan model provides the nearshore (reef) bathymetry for water depths between mean low tide to mean sea level and the island's coastal topography (including the coastal ridges). The Generic Mapping Tool ${ }^{63}$ interpolates the combined elevation and bathymetry data on a $7.5 \mathrm{~m}$ by $7.5 \mathrm{~m}$ grid, which was also used as a computation grid in the model. Offshore waters are truncated to $h=60 \mathrm{~m}$. Similar to the computations in D3D, the hydrodynamic boundary conditions are characterized by a TMA-wave spectrum with a significant wave height of $H_{s}=2.3 \mathrm{~m}$, a peak period of $T_{p}=17 \mathrm{~s}$ and peak directions of $\theta_{p}=202.5^{\circ}$ and $\theta_{p}=135^{\circ}$ respectively.

Since this study focuses on the wave driven longshore currents, ocean circulation around Fuvahmulah and the tidal current velocity was disregarded for sediment transport processes (for further information, see Supplementary Materials). This can be considered standard practice when regarding longshore sediment transport and confirms that longshore sediment transport mainly depends on incident waves, while tidal and ocean currents are of minor importance ${ }^{64}$.

Both numerical approaches reveal the impact of the regional wave climate on sediment transport and thus on erosion. But some limitations apply to the results of the numerical models: The wave input is based on storm wave heights of two peak directions, while moderate seas also have an influence on sediment transport and beach restoration $^{65}$. Furthermore, D3D is able to reconstruct experimental and hindcast data of sandy beaches ${ }^{61}$, but application on reef island morphodynamics is scarce ${ }^{66}$. For Fuvahmulah, D3D does not implement port structures in its bathymetry, to mimic the natural sediment pathways. The coarse resolution and the idealized bathymetry give a general concept of sediment movement on the reef rather than quantitative volumes of transported sediment. Still, the coarse model is able to reconstruct typical, process-based morphodynamic behavior for an environment like the Fuvahmulah reef ${ }^{24}$. The $2 \mathrm{DH}$ wave model comprises a more detailed study with and without the port structure. But the results must be interpreted with caution: The 2DH approach calculates current velocities but does 
not yield transported sediment volumes. Erosion and sedimentation depend on more than only current velocities ${ }^{24}$. For example, research on organism scale shows that sediment transport on coral reef bottoms is complex ${ }^{62}$. But current velocities are the main driver behind sediment transport phenomena and velocity gradients hint at hotspots of erosion and sedimentation ${ }^{60}$. With this in mind, the computed wave-induced currents are able to illustrate the role of the southeastern reef area under the given wave climate for the sediment transport around Fuvahmulah. They also facilitate a process-based understanding of the seaport's impact on the adjacent coastline, even without increased sea level or varied wave heights.

\section{Societal aspects}

The analysis of the societal dynamics is based on a mixed-methods approach to convey the social and governance aspects influencing coastal protection and climate change related topics. The approach encompasses (1) a literature review and content analysis of climate change adaptation and coastal protection literature in the Maldives, (2) two surveys with the local population, which are complemented by (3) semi-structured interviews with relevant actors involved in coastal management on the local as well as on the national level. All participants gave their voluntary consent to participate and have been informed about the objective of the research. The collected data of the second survey and the interviews were analyzed via a structuring content analysis in the software program MAXQDA ${ }^{67}$. This content analysis categorizes the interview's responses and those of open questions in the surveys into codes and subcodes, developed in a concept-driven and data-driven approach ${ }^{68}$. The concept-driven or deductive approach follows a categorization structure established before the field campaign. However, the possibility to respond to open-ended questions also requires post-processing of the responses based on their content - resulting in a data-driven approach.

The first survey and interviews took place from March to April 2017 and were synchronized with the first field campaign, measuring topographic and hydrodynamic data. Intermediate results from both work packages and the associated discussions led to interdisciplinary insights, considered in the second survey (January to February 2019).

\section{Literature review}

The literature review was conducted by content analysis. The analysis focused on publications relevant to climate change adaptation and coastal protection in the Maldives, including peer-reviewed papers, legislation and regulations, as well as gray literature. Legislation and regulations were primarily identified with the support of actors in the Maldives coastal governance system through the semi-structured interviews, ensuring their relevance and completeness. The literature review also encompasses previous EIAs on coastal projects in the Maldives, as these are required to list the legislations and regulations that are applicable to the projects. Most legislation and regulations are available in an English version on the website of the respective ministry, however, documents in the local language Dhivehi have not been considered. The analyzed gray literature covered EIAs, available through the Maldives Environmental Protection Agency (EPA), as well as reports from the Government of the Maldives, Nongovernmental Organizations (NGOs) and intergovernmental organizations, such as the United Nations Development Programme (UNDP) Maldives. Special attention was paid to reports, EIAs, and ESIAs concerning Fuvahmulah's seaport or explicit climate change adaptation measures on the island (see Tab. 2). The documents were analyzed via a qualitative content analysis ${ }^{68}$, which focused on the following thematic codes or categories in the context of the coastal governance system in the Maldives: (1) distribution of responsibilities among actors in the context of coastal protection, (2) history of coastal protection measures, (3) framing of coastal protection in the climate change discussion and (4) framing of coastal protection in the climate change discussion framing of coastal protection in the climate change discussion. The analysis disclosed knowledge gaps in the literature and demonstrated the need for an exploratory and qualitative research approach. Therefore, the study also contains population surveys and semi-structured interviews.

\section{Survey}

Two surveys with semi-standardized questionnaires were conducted in Fuvahmulah. The first survey focused on four topics: (1) the local's understanding of the environment and the coast, (2) their perception of environmental issues with a focus on climate change impacts and comprehension of responsibilities for action, (3) the locals' perspectives 
Table 2. List of reports, EIAs and ESIAs on the environment, coastal protection and adaptation on Fuvahmulah. Laws and policy regulations on coastal risks and sea-level rise in the Maldives are assessed according to the framework of Gussmann and Hinkel ${ }^{23}$.

\begin{tabular}{ll}
\hline Title \& Author & Year \\
\hline Foahmulaku Beach Erosion Survey \& Coastal Protection Report & \\
Ministry of Environment, Energy and Water & 2006 \\
Survey of Climate Change Adaptation Measures in Maldives & \\
Ministry of Housing and Environment (MHE), United Nations Development Programme (UNDP) & 2011 \\
Wetland Conservation \& Coral Reef Monitoring Project & \\
Ministry of Housing and Environment (MHE), Climate Change Trust Fund (CCTF) & 2011 \\
Environment \& Social Assessment \& Management Framework & \\
Climate Change Adaptation Project & \\
Ministry of Environment and Energy (MEE) & 2014 \\
EIA Report For Coastal Protection at Gn. Fuvahmulah, Maldives & \\
Maldives Energy and Environmental Company (MEECO), Royal HaskoningDHV & \\
Report: Coastal protection at Gn. Fuvahmulah & \\
Royal HaskoningDHV & 2016 \\
Review of the Draft ESIA Report for the Fuvahmulah Coastal Protection & 2016 \\
Netherlands Commission for Environmental Assessment (NCEA) & \\
Review of the ToR for the ESIA Fuvahmulah Coastal Protection, Maldives & 2016 \\
Netherlands Commission for Environmental Assessment (NCEA) & \\
Environmental and Social Impact Assessment - Ecotourism Facility Development & \\
Sandcays, Ministry of Environment and Energy (MEE) & 2016 \\
\hline
\end{tabular}

on community life, and (4) their perspectives and attitudes towards coastal protection. The second survey focused on: (1) The locals' perceptions on community life, (2) their potential for engagement in environmental and coastal protection activities, and (3) how politics shape the way coastal issues are addressed.

The surveys involved going from door-to-door in all eight wards of the island and were supported by local research assistants. The sample size of each survey is equivalent to about every eighth household on the island, while household selection was done by previous randomized sampling, yielding an unbiased representation of local households. Interviewees were not working in local coastal management. The first survey had 116 participants between the age of 14 and 86, while the second survey was answered by 98 inhabitants of Fuvahmulah between 14 and 84 years old. The lower threshold of 14 years results from experience gathered on the island and in consultancy with the local research assistants - persons over 14 start joining environmental activities without their parents guidance and thus are considered aware of Fuvahmulah's environmental situation.

The questionnaire of each survey contained closed and open questions (see supplementary materials). For closed questions, the questionnaire provides predefined answers, which were analyzed with methods of descriptive analytics. In contrast to closed questions, open questions require the participant to respond freely to the question. The answers were categorized and coded ${ }^{68}$ after the survey to quantify the results and identify important response patterns. In both surveys, the individual interview time varied strongly, ranging from 20 to 90 minutes. This can be explained by the qualitative approach of the surveys, utilizing open questions and the varying length and depth of answers which depended, for example, on the interviewee's interest in the topics.

\section{Interviews}

In each field trip, the interviews of Fuvahmulah's population were complemented by semi-structured interviews with actors on the national and local level being involved in the management of coastal issues in the Maldives. The selection of interview partners is based on their profession and their expertise on the subject (purposive sampling). 
Using this non-random technique was necessary due to the limited number of actors in coastal governance, while obtaining the required information to compare the varying opinions and interests among those actors regarding coastal protection.

On the national level, interview partners were representatives of the Ministry of Environment and Energy (renamed to Ministry of Environment in 2018), members of non-governmental and intergovernmental organizations that are active in the climate change adaptation and coastal management fields, as well as local researchers. Interviews with non-government actors gave in-depth and critical perspectives on the way environmental and coastal issues are addressed by government entities. This information is especially important as it helps to identify informal institutions, such as norms and attitudes towards specific responses to coastal problems that become effective and influence the way coastal problems are addressed.

On the local level, interview partners are current and former members of Fuvahmulah's council and representatives of non-governmental organizations.

In summary, the results of this study are based on 32 interviews with 18 interviews with actors on the national level (10 government, 8 non-governmental or intergovernmental organizations and researchers) and 14 on the local level (8 government, 6 non-governmental organizations). The interviews of the first field trip addressed (1) societal dealings with environmental problems, (2) coastal management with focus on decision-making processes, (3) community involvement and public awareness, and (4) politics and climate change. The second interview guide focused on (1) the community in the Maldives, (2) community engagement, and (3) coastal governance. The interviews lasted between 30 and 120 minutes. Due to the political situation in the Maldives and the small number of experts in this field, not all interviewees agreed to be recorded, but memos and notes capture the interview's statements. Recorded interviews were transcribed before analysis. In addition, the interviews were fully anonymized - except for the ministry officials - in order to protect the identity of the informants.

\section{Data availability}

The field data supporting the findings of this study is publicly available ${ }^{69}$ through doi.org/10.5281/zenodo.4304049. Wave climate data is available from the respective services and homepages of CAWCR, ECMWF and NOAA as mentioned in Table 1.

\section{Code availability}

The Boussinesq Ocean and Surf Zone (BOSZ) model is available through Volker Roeber upon reasonable request. Delft3D is open-source and available through Deltares (oss.deltares.nl/web/delft3d). The corresponding author provides the scripts for data post processing and visualization, written with Python 3.7 in Jupyter Notebooks also upon reasonable request. 


\section{References}

1. Nurse, L. A. et al. Small Islands. In Barros, V. R. et al. (eds.) Climate Change 2014: Impacts, Adaptation, and Vulnerability. Part B: Regional Aspects. Contribution of Working Group II to the Fifth Assessment Report of the Intergovernmental Panel of Climate Change, 1613-1654 (Cambridge University Press, Cambridge, United Kingdom and New York, NY, USA, 2014).

2. Magnan, A. et al. Integrative cross-chapter box on low-lying islands and coasts. In Pörtner, H.-O. et al. (eds.) Special Report on Ocean and Cryosphere in a Changing Climate (In press, 2019).

3. Oppenheimer, M. et al. Sea Level Rise and Implications for Low Lying Islands, Coasts and Communities. In Pörtner, H.-O. et al. (eds.) IPCC Special Report on the Ocean and Cryosphere in a Changing Climate (In press, 2019).

4. Storlazzi, C. D., Elias, E. P. \& Berkowitz, P. Many atolls may be uninhabitable within decades due to climate change. Sci. Reports 5, DOI: 10.1038/srep14546 (2015).

5. Kench, P. S. \& Mann, T. Reef island evolution and dynamics: Insights from the indian and pacific oceans and perspectives for the spermonde archipelago. Front. Mar. Sci. 4, 145, DOI: 10.3389/fmars.2017.00145 (2017).

6. Moustahfid, H., Marsac, F. \& Gangopadhyay, A. Impacts of climate change on fisheries and aquaculture Synthesis of current knowledge, adaptation and mitigation options, vol. 627, Technical Paper Climate change impacts, vulnerabilities and adaptations: Western Indian Ocean marine fisheries (Fisheries and Aquaculture Department of the Food and Agriculture Organization of the United Nations, Rome, Italy, 2018). ISSN 2070-7010.

7. Kench, P. S. Compromising reef island shoreline dynamics: Legacies of the engineering paradigm in the maldives. In Cooper, J. A. G. \& Pilkey, O. H. (eds.) Pitfalls of Shoreline Stabilization: Selected Case Studies, 165-186, DOI: 10.1007/978-94-007-4123-2_11 (Springer Netherlands, Dordrecht, 2012).

8. Luijendijk, A. et al. The state of the world's beaches. Sci. Reports 8, DOI: 10.1038/s41598-018-24630-6 (2018).

9. Duvat, V. K. E. \& Magnan, A. K. Rapid human-driven undermining of atoll island capacity to adjust to ocean climate-related pressures. Sci. Reports 9, DOI: 10.1038/s41598-019-51468-3 (2019).

10. Patrício, J., Elliott, M., Mazik, K., Papadopoulou, K.-N. \& Smith, C. J. DPSIR-Two Decades of Trying to Develop a Unifying Framework for Marine Environmental Management? Front. Mar. Sci. 3, 177, DOI: 10.3389/fmars.2016.00177 (2016).

11. IPCC. The IPCC Response Strategies. In Bernthal, F. et al. (eds.) First Assessment Report (FAR), 269 (Island Press, Cambridge, United Kingdom and New York, NY, USA, 1990).

12. Ratter, B. M., Petzold, J. \& Sinane, K. Considering the locals: coastal construction and destruction in times of climate change on Anjouan, Comoros. Nat. Resour. Forum 40, 112-126, DOI: 10.1111/1477-8947.12102 (2016). onlinelibrary.wiley.com/doi/pdf/10.1111/1477-8947.12102.

13. Magnan, A. K. \& Duvat, V. K. E. Towards adaptation pathways for atoll islands. Insights from the Maldives. Reg. Environ. Chang. 20, DOI: 10.1007/s10113-020-01691-w (2020).

14. Petzold, J. \& Magnan, A. K. Climate change: thinking small islands beyond Small Island Developing States (SIDS). Clim. Chang. 152, 145-165, DOI: 10.1007/s10584-018-2363-3 (2019).

15. Petzold, J., Ratter, B. M. W. \& Holdschlag, A. Competing knowledge systems and adaptability to sea-level rise in The Bahamas. Area 50,91-100, DOI: 10.1111/area.12355 (2018). rgs-ibg.onlinelibrary.wiley.com/doi/pdf/ 10.1111/area.12355.

16. Hamin, E. et al. Pathways to coastal resiliency: The adaptive gradients framework. Sustainability 10, 2629, DOI: $10.3390 / \mathrm{su} 10082629$ (2018). 
17. Cai, W. et al. Increased frequency of extreme indian ocean dipole events due to greenhouse warming. Nature 510, 254-258, DOI: 10.1038/nature13327 (2014).

18. Dangendorf, S. et al. Persistent acceleration in global sea-level rise since the 1960s. Nat. Clim. Chang. 9, 705-710, DOI: 10.1038/s41558-019-0531-8 (2019).

19. Ratter, B., Hennig, A. \& Zahid. Challenges for shared responsibility - Political and social framing of coastal protection transformation in the Maldives. DIE ERDE - Journal of the Geographical Society of Berlin 150, 169-183 (2019).

20. Noble, I. et al. Adaptation needs and options. In Field, C. et al. (eds.) Climate Change 2014: Impacts, Adaptation, and Vulnerability. Part A: Global and Sectoral Aspects. Contribution of Working Group II to the Fifth Assessment Report of the Intergovernmental Panel on Climate Change, vol. AR 5, 833-868. The Intergovernmental Panel on Climate Change (Cambridge University Press, Cambridge, United Kingdom and New York, NY, USA, 2015).

21. IPCC. Climate Change 2014: Impacts, Adaptation, and Vulnerability (Cambridge University Press, Cambridge, United Kingdom and New York, NY, USA, 2015).

22. Zubair, S., Bowen, D. \& Elwin, J. Not quite paradise: Inadequacies of environmental impact assessment in the Maldives. Tour. Manag. 32, 225 - 234, DOI: 10.1016/j.tourman.2009.12.007 (2011).

23. Gussmann, G. \& Hinkel, J. A framework for assessing the potential effectiveness of adaptation policies: Coastal risks and sea-level rise in the Maldives. Environ. Sci. \& Policy 115, 35 - 42, DOI: https://doi.org/10.1016/j. envsci.2020.09.028 (2021).

24. David, C. G. \& Schlurmann, T. Hydrodynamic drivers and morphological responses on small coral islands - The Thoondu spit on Fuvahmulah, the Maldives. Front. Mar. Sci. 7, 885, DOI: 10.3389/fmars.2020.538675 (2020).

25. Shaig, A. Survey of Climate Change Adaptation Measures in Maldives - Integration of Climate Change Risks into Resilient Island Planning in the Maldives Project. Final Report, Ministry of Housing and Environment, the Maldives (MEE), United Nations Development Programme (UNDP) (2011).

26. Kench, P. S., Brander, R. W., Parnell, K. E. \& McLean, R. F. Wave energy gradients across a Maldivian atoll: Implications for island geomorphology. Geomorphology 81, 1 - 17, DOI: doi.org/10.1016/j.geomorph.2006.03. 003 (2006).

27. NBS. Maldives Population and Housing Census. Summary, National Bureau of Statistics (NBS), Ministry of Finance and Treasury, Male' 20379, Republic of Maldives (2014).

28. MEE. Environment \& Social Assessment \& Management Framework Fuvahmulah. Climate Resilience and Environment Sustainability Project. Final Report, Ministry of Environment and Energy, the Maldives (MEE) (2014). Project carried out under the Climate Change Trust Fond, the World Bank; last accessed Dec. 27 through documents.worldbank.org.

29. Naeem, H. Foahmulaku Beach Erosion Survey \& Coastal Protection Report. Field Survey Report, Ministry of Environment, Energy and water (2006).

30. Kench, P. S. \& Brander, R. W. Response of reef island shorelines to seasonal climate oscillations: South Maalhosmadulu atoll, Maldives. J. Geophys. Res. Earth Surf. 111, DOI: 10.1029/2005JF000323 (2006). agupubs.onlinelibrary.wiley.com/doi/pdf/10.1029/2005JF000323.

31. Schöne, T., Esselborn, S., Rudenko, S. \& Raimondo, J.-C. Radar altimetry derived sea level anomalies the benefit of new orbits and harmonization. In Flechtner, F. M. et al. (eds.) System Earth via GeodeticGeophysical Space Techniques, 317-324, DOI: 10.1007/978-3-642-10228-8_25 (Springer Berlin Heidelberg, Berlin, Heidelberg, 2010).

32. Hemer, M. A., Katzfey, J. \& Trenham, C. E. Global dynamical projections of surface ocean wave climate for a future high greenhouse gas emission scenario. Ocean. Model. 70, 221 - 245, DOI: doi.org/10.1016/j.ocemod. 2012.09.008 (2013). Ocean Surface Waves. 
33. IPCC. Summary for policymakers. In Stocker, T. et al. (eds.) Climate Change 2013: The Physical Science Basis. Contribution of Working Group I to the Fifth Assessment Report of the Intergovernmental Panel on Climate Change, 1-30, DOI: 10.1017/CBO9781107415324.004 (Cambridge University Press, Cambridge, United Kingdom and New York, NY, USA, 2013).

34. Hemer, M. A., Fan, Y., Mori, N., Semedo, A. \& Wang, X. L. Projected changes in wave climate from a multi-model ensemble. Nat. Clim. Chang. 3, 471-476, DOI: 10.1038/nclimate1791 (2013).

35. Ryan, E. J., Hanmer, K. \& Kench, P. S. Massive corals maintain a positive carbonate budget of a Maldivian upper reef platform despite major bleaching event. Sci. Reports 9, DOI: 10.1038/s41598-019-42985-2 (2019).

36. Malatesta, S. \& Schmidt, M. Environmental policy and climate change vulnerability in the Maldives: From the 'lexicon of risk' to social response to change. Island Stud. J. 12, 53-70, DOI: 10.24043/isj.5 (2017).

37. Hoogduin, L. Coastal protection at Gn. Fuvahmulah. Deliverable - 2e. Technical Design, Royal Haskoning DHV, Amersfoort, the Netherlands (2016).

38. Saleem, A. Environmental impact assessment report for coastal protection at gn. fuvahmulah, maldives. Technical Report, Maldives Energy and Environmental Company (MEECO), Male', Republic of Maldives (2016). In Association with Royal HaskoningDHV.

39. Ferrario, F. et al. The effectiveness of coral reefs for coastal hazard risk reduction and adaptation. Nat. Commun. 5, DOI: 10.1038/ncomms4794 (2014).

40. Perry, C. T. et al. Caribbean-wide decline in carbonate production threatens coral reef growth. Nat. Commun. 4, DOI: 10.1038/ncomms2409 (2013).

41. Duvat, V. K. et al. Trajectories of exposure and vulnerability of small islands to climate change. WIREs Clim. Chang. 8, e478, DOI: 10.1002/wcc.478 (2017).

42. Bisaro, A. \& Hinkel, J. Governance of social dilemmas in climate change adaptation. Nat. Clim. Chang. 6, 354-359, DOI: 10.1038/nclimate2936 (2016).

43. van Slobbe, E. et al. Building with Nature: in search of resilient storm surge protection strategies. Nat. Hazards 66, 1461-1480, DOI: 10.1007/s11069-013-0612-3 (2013).

44. Haasnoot, M., Kwakkel, J. H., Walker, W. E. \& ter Maat, J. Dynamic adaptive policy pathways: A method for crafting robust decisions for a deeply uncertain world. Glob. Environ. Chang. 23, 485 - 498, DOI: https://doi.org/10.1016/j.gloenvcha.2012.12.006 (2013).

45. Westoby, M., Brasington, J., Glasser, N., Hambrey, M. \& Reynolds, J. 'Structure-from-Motion' photogrammetry: A low-cost, effective tool for geoscience applications. Geomorphology 179, $300-314$, DOI: doi.org/10.1016/j. geomorph.2012.08.021 (2012).

46. Roeber, V. \& Bricker, J. D. Destructive tsunami-like wave generated by surf beat over a coral reef during typhoon haiyan. Nat. Commun. 6, DOI: 10.1038/ncomms8854 (2015).

47. Bruno, M. F., Molfetta, M. G., Totaro, V. \& Mossa, M. Performance assessment of ERA5 wave data in a swell dominated region. J. Mar. Sci. Eng. 8, 214, DOI: 10.3390/jmse8030214 (2020).

48. Durrant, T., Hemer, M., Smith, G., Trenham, C. \& Greenslade, D. CAWCR Wave Hindcast - Aggregated Collection. v1 (2019). Last accessed: 2020-03-29, permalink: hdl.handle.net/102.100.100/137152?index=1.

49. Tolman, H. L. User manual and system documentation of WAVEWATCH III version 3.14. Technical Note 276, NOAA / NWS / NCEP / MMAB (1999).

50. Saha, S. et al. The NCEP Climate Forecast System Reanalysis. Bull. Am. Meteorol. Soc. 91, 1015-1058, DOI: 10.1175/2010BAMS3001.1 (2010). doi.org/10.1175/2010BAMS3001.1.

51. WAMDIG. The WAM Model-A Third Generation Ocean Wave Prediction Model. J. Phys. Oceanogr. 18, 1775-1810, DOI: 10.1175/1520-0485(1988)018<1775:TWMTGO>2.0.CO;2 (1988). doi.org/10.1175/ 1520-0485(1988)018<1775:TWMTGO>2.0.CO;2. 
52. ECMWF. ECMWF Wave Model. In IFS Documentation - Cy41r2, chap. VII, 1-83 (European Centre for Medium-Range Weather Forecasts (ECMWF), Shinfield Park, Reading, RG2 9AX, England, 2016).

53. Copernicus Climate Change Service. ERA5: Fifth generation of ECMWF atmospheric reanalyses of the global climate, DOI: 10.24381/cds.adbb2d47 (2017). Copernicus Climate Change Service Climate Data Store (CDS). Last date of access: 2019-12-06.

54. Hemer, M., Trenham, C., Durrant, T. \& Greenslade, D. CAWCR Global wind-wave 21 st century climate projections. v1 (2015). Last accessed: 2020-03-29, DOI: doi.org/10.4225/08/55C991CC3F0E8.

55. Muhammed Naseef, T. \& Sanil Kumar, V. Climatology and trends of the Indian Ocean surface waves based on 39-year long ERA5 reanalysis data. Int. J. Climatol. 40, 979-1006, DOI: 10.1002/joc.6251 (2020). rmets. onlinelibrary.wiley.com/doi/pdf/10.1002/joc.6251.

56. Wiese, A. et al. Synergy of wind wave model simulations and satellite observations during extreme events. Ocean. Sci. 14, 1503-1521, DOI: 10.5194/os-14-1503-2018 (2018).

57. Hildebrandt, A., Schmidt, B. \& Marx, S. Wind-wave misalignment and a combination method for directiondependent extreme incidents. Ocean. Eng. 180, 10 - 22, DOI: doi.org/10.1016/j.oceaneng.2019.03.034 (2019).

58. Arns, A. et al. Non-linear interaction modulates global extreme sea levels, coastal flood exposure, and impacts. Nat. Commun. 11, DOI: 10.1038/s41467-020-15752-5 (2020).

59. Timmermans, B. W., Gommenginger, C. P., Dodet, G. \& Bidlot, J.-R. Global wave height trends and variability from new multimission satellite altimeter products, reanalyses, and wave buoys. Geophys. Res. Lett. 47, e2019GL086880, DOI: 10.1029/2019GL086880 (2020). E2019GL086880 10.1029/2019GL086880.

60. van Rijn, L. C. Principles of Sedimentation and Erosion Engineering in Rivers, Estuaries and Coastal Seas (Aqua Publications, Amsterdam, The Netherlands, 2005).

61. Lowe, R. J., Falter, J. L., Monismith, S. G. \& Atkinson, M. J. A numerical study of circulation in a coastal reef-lagoon system. J. Geophys. Res. Ocean. 114, DOI: 10.1029/2008JC005081 (2009). agupubs.onlinelibrary. wiley.com/doi/pdf/10.1029/2008JC005081.

62. Pomeroy, A. W. M. et al. Sediment transport in the presence of large reef bottom roughness. J. Geophys. Res. Ocean. 122, 1347-1368, DOI: 10.1002/2016JC011755 (2017). agupubs.onlinelibrary.wiley.com/doi/pdf/10. 1002/2016JC011755.

63. Wessel, P. \& Luis, J. F. The GMT/MATLAB Toolbox. Geochem. Geophys. Geosystems 18, 811-823, DOI: 10.1002/2016GC006723 (2017). agupubs.onlinelibrary.wiley.com/doi/pdf/10.1002/2016GC006723.

64. Burcharth, H. F., Hawkins, S. J., Zanuttigh, B. \& Lamberti, A. Design tools related to engineering. In Burcharth, H. F., Hawkins, S. J., Zanuttigh, B. \& Lamberti, A. (eds.) Environmental Design Guidelines for Low Crested Coastal Structures, 203 - 333, DOI: doi.org/10.1016/B978-008044951-7/50033-6 (Elsevier Science Ltd, Oxford, 2007).

65. Barnard, P. L. et al. Extreme oceanographic forcing and coastal response due to the 2015-2016 El Niño. Nat. Commun. 8, DOI: 10.1038/ncomms14365 (2017).

66. Shope, J. B. \& Storlazzi, C. D. Assessing morphologic controls on atoll island alongshore sediment transport gradients due to future sea-level rise. Front. Mar. Sci. 6, 245, DOI: 10.3389/fmars.2019.00245 (2019).

67. Kuckartz, U. \& Rädiker, S. Analyzing Qualitative Data with MAXQDA (Springer, Wiesbaden, Germany, 2019).

68. Kuckartz, U. Qualitative Text Analysis: A Systematic Approach. In Kaiser, G. \& Presmeg, N. (eds.) Compendium for Early Career Researchers in Mathematics Education, 181-197, DOI: 10.1007/978-3-030-15636-7_ 8 (Springer International Publishing, Cham, 2019).

69. David, C. G., Ballesteros, P. \& Schlurmann, T. Coastal Digital Elevation Models and Transects of the Reef Island Fuvahmulah, the Maldives [Dataset]. Zenodo DOI: 10.5281/zenodo.4304049 (2020). 


\section{Author Contributions}

CGD conducted the natural science part of field campaigns, research and analysis, while AH carried out the corresponding social science part. VR developed the BOSZ model used in this study and supervised the numerical modeling. TS and BR (co-)designed the research project, were responsible for funding resources and reporting and provided guidance throughout the entire research. CGD wrote the manuscript with input from AH. BR, VR and TS edited and contributed to the final manuscript. $\mathrm{Z}$ helped in designing the research project, coordinating the field surveys and evaluating the local perspective.

\section{Conflict of Interest Statement}

The authors declare that the research was conducted in the absence of any commercial or financial relationships that could be construed as a potential conflict of interest.

\section{Acknowledgments}

This study took place in the project "Dealing with change in SIDS: societal action and political reaction in sea level change adaptation in Small Island Developing States (DICES)", grant no. SCHL 503/17-1 (CGD, TS) and RA 585/19-1 (AH, BR). The project is framed within the priority programm (SPP-1889) - regional sea level change and society of the German Research Foundation (Deutsche Forschungsgemeinschaft, DFG).

Volker Roeber acknowledges financial support from the Isite program Energy Environment Solutions (E2S), the Communauté d'Agglomération Pays Basque (CAPB) and the Communauté Région Nouvelle Aquitaine (CRNA) for the chair position HPC-Waves; as well as the support from the University of Hawai'i at Mānoa for the Affiliate Graduate Faculty position.

Zahid was employed as Deputy Director General Climatology at the Maldives Meteorological Service (MMS) at the time of the project, but retired from his position.

The authors would like to thank Ali Ahmed, Pablo Ballesteros, Tatiana Ivanova, René Klein, Nina Kohl, Manò Schütt, Ibrahim Shiyan (Panda) as well as Marion and Uwe Zander for their help in the field campaigns. In the Maldives, the authors were supported by the Maldives Meteorological Service (MMS), Fuvahmulah Island Council and Fuvahmulah DIVE School. The authors also thank Tilo Schöne of GFZ Potsdam, providing the SRA data as well as Jean Bidlot, Mark Hemer and Todd Spindler for their help in accessing climate reanalysis data. Also, Elisa Casella and Alessio Rovere gave valuable insights and feedback to UAV-based photogrammetry, while Tobias Kersten helped with geodetic questions before the third field campaign and with post-processing the GNSS data. Furthermore, the authors acknowledge Jannek Gundlach, Astrid Kartes and Jonas Briese for their support with Delft3D. 


\section{Acronyms}

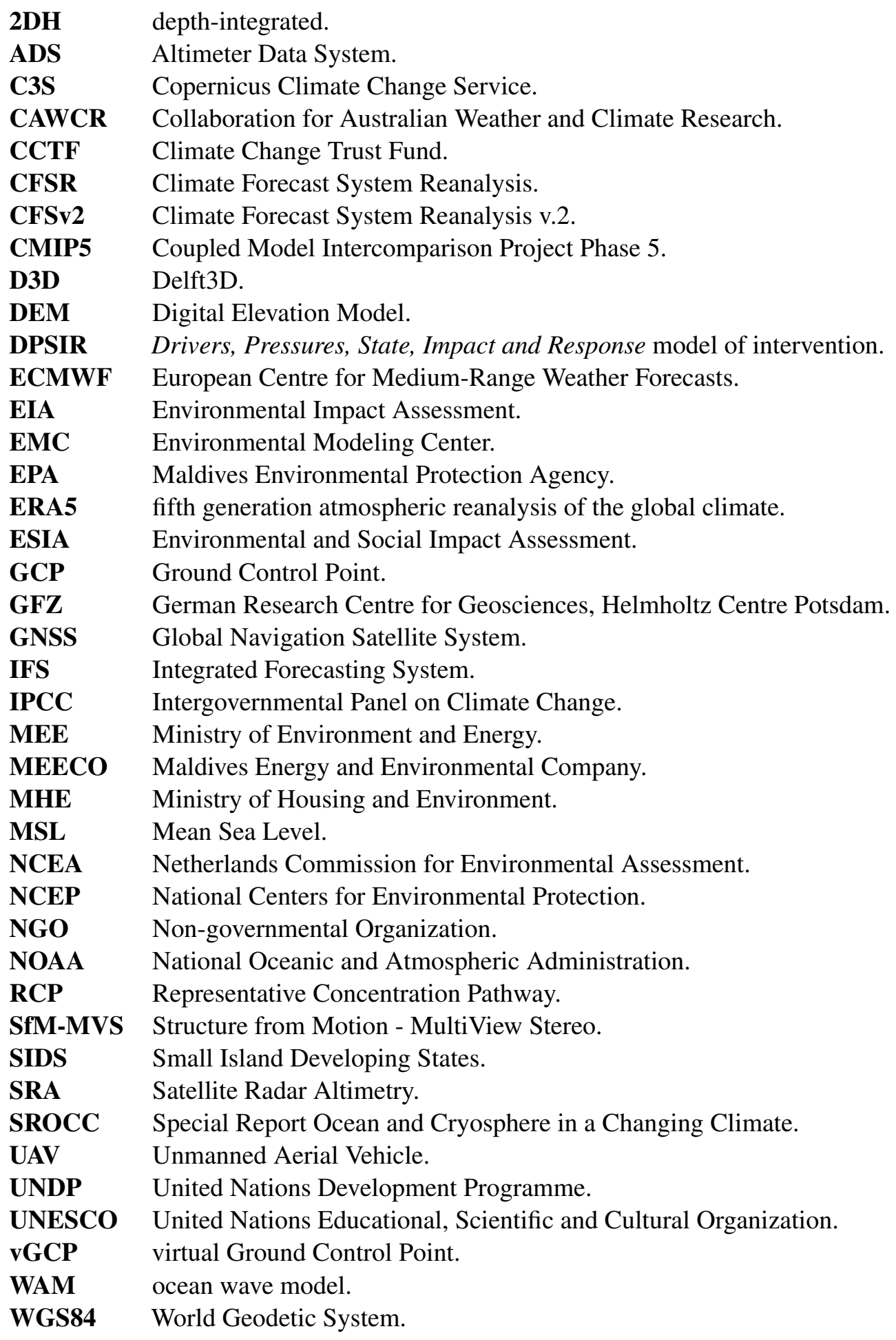




\section{Supplementary Information for the manuscript:}

Climate change induced effects or maldevelopment: small islands and conflicting attribution of root causes

\section{Gabriel David ${ }^{1, *}$, Arne Hennig ${ }^{2}$, Beate M. W. Ratter ${ }^{2}$, Volker Roeber ${ }^{3,4}$, Zahid $^{5}$, and Torsten Schlurmann ${ }^{1}$}

${ }^{1}$ Ludwig-Franzius-Institute for Hydraulics, Estuarine and Coastal Engineering, Leibniz Universität Hannover, Nienburger Straße 4, 30167 Hanover, Germany

${ }^{2}$ Institute for Geography, Department for Earth System Sciences, Universität Hamburg, Bundesstraße 55, 20146 Hamburg, Germany

${ }^{3}$ E2S UPPA, Chair HPC-Waves, SIAME, Université de Pau et des Pays de l'Adour, Allée du parc Montaury, Anglet, France

${ }^{4}$ University of Hawai'i at Mānoa, Department of Oceanography, 1000 Pope Road, Honolulu, HI 96822, USA

5 formerly Maldives Meteorological Service, Hulhule' 22000, Maldives

*david@lufi.uni-hannover.de 


\section{Supplementary Information}

\section{S1 Photoscan Settings}

Photoscan is performing a three-dimensional, virtual reconstruction of the coastal areas of Fuvahmulah, based on the aerial images, recorded in three field campaigns. Tab. S1 shows the settings within the software for each reconstruction. The settings resulted in digital elevation models (DEMs) with a similar resolution of $\approx 3.5 \mathrm{cmpx}^{-1}$.

Table S1. Photoscan settings to obtain digital elevation models from the coastal areas, recorded in each field campaign.

\begin{tabular}{llll}
\hline & $\begin{array}{l}\text { 2017 March } \\
\text { Dry Season }\end{array}$ & $\begin{array}{l}\text { 2017 September } \\
\text { Wet Season }\end{array}$ & $\begin{array}{l}\text { 2019 March } \\
\text { Dry Season }\end{array}$ \\
\hline $\begin{array}{llll}\text { Alignment } \\
\text { Accuracy }\end{array}$ & & & \\
$\begin{array}{l}\text { Generic preselection } \\
\text { Reference preselection }\end{array}$ & Yes & Medium & High \\
Key point limit & Yes & Yes & Yes \\
$\begin{array}{l}\text { Tie point limit } \\
\text { Adaptive camera }\end{array}$ & 40000 & Yes & Yes \\
model fitting & No & 40000 & 40000 \\
$\begin{array}{l}\text { Optimization Para- } \\
\text { meters }\end{array}$ & $\mathrm{f}, \mathrm{cx}, \mathrm{cy}, \mathrm{k} 1-\mathrm{k} 4$ & $\mathrm{f}, \mathrm{b} 1, \mathrm{~b} 2, \mathrm{cx}, \mathrm{cy}$, & $\mathrm{f}, \mathrm{cx}, \mathrm{cy}, \mathrm{k} 1-\mathrm{k} 4$ \\
& $(\mathrm{k} 1-\mathrm{k} 4, \mathrm{p} 1-\mathrm{p} 4)^{1}$ & $\mathrm{k} 1-\mathrm{k} 4, \mathrm{p} 1-\mathrm{p} 4$ &
\end{tabular}

\section{Dense Point Cloud}

Quality

Depth filtering

\section{Mesh}

Surface type

Source data

Quality

Depth filtering

\section{DEM}

Source data

\section{Ultra High}

Aggressive

Height field

Dense Point Cloud

Ultra High

Aggressive
Medium

Aggressive

Height field

Dense Point Cloud

Medium

Aggressive
High

Aggressive
Height field

Dense Point Cloud

High

Aggressive

Mesh Dense cloud Mesh

\section{Software}

Agisoft Photoscan Version

1.4.5 build 7354

1.4.5 build 7354

1.4.5 build 7354

Platform

Linux (Ubuntu) 64 Linux (Ubuntu) 64 Linux (Ubuntu) 64

\footnotetext{
${ }^{1}$ for the adjacent $350 \mathrm{~m}$ north of the harbour.
} 
David, et al. (2020): Climate change induced effects or maldevelopment.

These are supplementary materials to a non-peer reviewed preprint submitted to EarthArXiv.

\section{S2 Wave Statistics}

Tables S2 and S3 display the associated median and IQR values for the boxplots of the significant wave height $H_{S}$ around Fuvahmulah, as seen in Fig. 5 of the main manuscript. The data in Table S2 is based on the Collaboration for Australian Weather and Climate Research (CAWCR) wave hindcast collection ${ }^{1}$ for the time period $1979-2019$. Table S3 contains statistical values for the Representative Concentration Pathway (RCP) projections 4.5 and 8.5 of the CAWCR wave projections ${ }^{2}$ for the time frame $2081-2100$ and the associated historical $H_{S}$ values for the period 1986 - 2005. The methods of the main article contain further information on the wave data collection.

Table S2. Statistic values of the significant wave height $H_{s}$ for the CAWCR wave hindcast data set (1979 - 2019), as shown in Fig. 5a of the main article

\begin{tabular}{lcc|lcc}
\hline Month & Median $\mathbf{H}_{\mathbf{s}}(\mathbf{m})$ & IQR of $\mathbf{H}_{\mathbf{s}}(\mathbf{m})$ & Month & Median $\mathbf{H}_{\mathbf{s}}(\mathbf{m})$ & IQR of $\mathbf{H}_{\mathbf{s}}(\mathbf{m})$ \\
\hline January & 1.04 & 0.21 & July & 1.71 & 0.33 \\
February & 0.99 & 0.24 & August & 1.64 & 0.31 \\
March & 0.98 & 0.23 & September & 1.48 & 0.31 \\
April & 1.15 & 0.33 & October & 1.37 & 0.40 \\
May & 1.38 & 0.35 & November & 1.23 & 0.39 \\
June & 1.62 & 0.34 & December & 1.07 & 0.29 \\
\hline
\end{tabular}

Table S3. Statistic values of the significant wave height $H_{S}$ for the historical $(1986$ - 2005) and RCP data set (2081 -2100), as shown in Fig. $5 f$ of the main article

\begin{tabular}{lcc}
\hline RCP & Median $\mathbf{H}_{\mathbf{s}}(\mathbf{m})$ & IQR of $\mathbf{H}_{\mathbf{s}}(\mathbf{m})$ \\
\hline Historical & 1.62 & 0.60 \\
RCP 4.5 & 1.63 & 0.61 \\
RCP 8.5 & 1.62 & 0.61 \\
\hline
\end{tabular}




\section{S3 Current Velocities}

Since the study focuses on the wave driven longshore currents, ocean circulation around Fuvahmulah and the tidal current velocity was disregarded for sediment transport processes. To justify this simplification, the following section compares velocities from ocean circulation, tidal current velocities and wave-induced currents with each other. The velocity of the ocean circulation was derived from monthly means of the European Centre for Medium-Range Weather Forecasts (ECMWF) Ocean ReAnalysis System 5 (ORAS5) reanalysis data-set ${ }^{3}$. This reanalysis data set calculates ocean (thermo-) dynamics and provides zonal and meridional velocities between $1979-2017$ at the position $0.0^{\circ}$ latitude and $73.4^{\circ}$ longitude (see Fig. 1 of the main article). According to the ORAS5 data, the median ocean circulation velocity In this region is $v_{m \text {,oceancirc }}=0.40 \mathrm{~m} \mathrm{~s}^{-1}$. The tidal current velocities are calculated by Delft3D (D3D). The simulation uses the University of Hawai'i Sea-Level Center (UHSLC) time-series ${ }^{4}$ of the neighboring Gan tide gauge ( $\sim 53 \mathrm{~km}$ away from Fuvahmulah). The D3D computations gave a median tidal current velocity of $v_{m \text {,tide }}=0.10 \mathrm{~m} \mathrm{~s}^{-1}$ with two peaks on the northwest $\left(v_{\max \text {,tide }}=0.30 \mathrm{~m} \mathrm{~s}^{-1}\right)$ and southeast-side $\left(v_{S E \text {,tide }}=0.28 \mathrm{~m} \mathrm{~s}^{-1}\right)$ of the island. These velocities are an order of magnitude below wave-induced currents (Fig. 7 of the main article) and thus can be neglected. This can be considered standard practice when regarding longshore sediment transport and confirms that longshore sediment transport mainly depends on incident waves, while tidal and ocean currents are of minor importance ${ }^{5}$. 


\section{S4 Selected Questions of the Questionnaires}

This section presents questions from the population survey, relevant for the study and their answer possibilities (closed questions) or most frequent answers (open questions), as well as associated codes and coding rules:

Question 1: The following list shows environmental issues concerning the coast. In your opinion, which 3 are the most pressing issues for Fuvahmulah?

(Closed-ended question; 3 responses possible per respondent, Respondents $=116$; Responses $=345$ )

- Waste $(22 \%)$

- Coral Bleaching (4\%)

- Declining fish populations (4\%)

- Flooding from rainfall $(7 \%)$

- Coral mining (2\%)

- Too ambitious fishing regulations (1\%)

- Declining rainfall (6\%)
- Erosion (27\%)

- Loss of land (7\%)

- Tsunami (1\%)

- Over-fishing (1\%)

- Sand mining (15\%)

- Coastal flooding (1\%)

- Other $(5 \%)$

Question 2: Have you observed any changes regarding the natural environment of Fuvahmulah in the past? If yes, please tell me what changes you have observed and since when.

(Hybrid question, Respondents $=116$ )

- Yes $(93 \%)$

(Open-ended, multiple responses possible per respondent; Respondents $=108$, Responses $=218$ ) Three most often named categories:

Codes (Coding rule, Example statement):

- Erosion (36\%)

Statement names erosion as an environmental change.

Example: "Due to high currents and huge waves - the soil from coastal areas are wiped out." (S1 063)

- Less trees $(15 \%)$

Statement states that less trees are found on the island as an environmental change.

Example "Trees are less." (S1 111)

- Temperature increase (7\%)

Statement names increase of temperature as an environmental change.

Example "It's getting hotter." (S1 084)

- No $(7 \%)$

Question 3: Do you feel safe to live in Fuvahmulah with regard to sea-level rise?

(Open-ended question, categorized, Respondents=116)

\section{Codes (Coding rule, Example statement):}

- Feels safe (52\%)

Statement demonstrating that the respondent feels safe on the island without doubt.

Example: "Currently the safest island in Maldives is Fuvahmulah because it has highest coast." (S1 026)

- Does not feel safe $(25 \%)$

Statement demonstrating that the respondent does not feel safe on the island.

Example: "No, it's not safe. I would prefer to move to some other island." (S1 076)

- Inconclusive (22\%)

Statement does not allow a clear valuation. 
Example: "If we get flood than we won't survive. This island's coasts are higher but middle of island is lower. It's like a bowl." (S1 073)

- Don't know (1\%)

Question 4: What are elements of the natural environment of Fuvahmulah that are important to you?

(Open-ended question, categorized, multiple responses possible per person; Respondents=116; Responses $=235$ )

Codes (Coding rule, Example statement):

- Trees $(17 \%)$

Statement mentions trees as an important element of the natural environment.

Example: " "Trees around the island." (S1 114)

- Beaches (8\%)

Statement mentions the beach as an important element of the natural environment.

Example: “"Nice beach.” (S1 049)

- Lakes $(8 \%)$

Statement mentions lakes as an important element of the natural environment.

Example: " "North lake near the house. It's very peaceful and in the evening, we go there with our children.” (S1 012)

Question 5: How is the community involved in the decision-making process regarding the development of the island?

(Open-ended question, categorized, Respondents=115)

Codes (Coding rule, Example statement):

- Regular involvement (17\%)

Statement arguing that community is included in the decision-making process.

Example: "Are included. Good things and bad things come out of it." (S1 031)

- Sporadic involvement (17\%)

Statement arguing that the community is included in the decision-making process from time to time or in limited ways.

Example: "Sometimes they take our opinions, and sometimes they just go ahead with it." (S1 033)

- Insufficient involvement (49\%)

Statement clearly demonstrating dissatisfaction with how the community is involved in the decision-making process.

Example: "Not involved. The leaders of the community decide it for themselves." (S1 107)

- Inconclusive (7\%)

Statement does not allow a clear valuation.

Example: "Don't know about other, but if I am asked for involvement, I go to help them." (S1 109)

- Don't know (8\%)

Question 6: Would you want to be more involved in the decision-making processes regarding the development of the island?

(Closed-ended question, Respondents=116)

- Yes $(83 \%)$

- No $(15 \%)$

- Don't know (2\%) 
David, et al. (2020): Climate change induced effects or maldevelopment.

These are supplementary materials to a non-peer reviewed preprint submitted to EarthArXiv.

\section{Data availability}

The field data supporting the findings presented in the main manuscript is publicly available ${ }^{6}$ through doi.org/10.5281/ zenodo.4304049. Wave climate data is available from the respective services and homepages of CAWCR ${ }^{1}$, while the ORAS5 ocean circulation data by the ECMWF is available through the University of Hamburg. Sea-level records are provided by UHSLC ${ }^{4}$ via doi.org/10.7289/V5V40S7W.

\section{Code availability}

Delft3D is open-source and available through Deltares (oss.deltares.nl/web/delft3d). The corresponding author provides the scripts for data post processing and visualization, written with Python 3.7.6 in Jupyter Notebooks upon reasonable request. 


\section{References}

1. Durrant, T., Hemer, M., Smith, G., Trenham, C. \& Greenslade, D. CAWCR Wave Hindcast - Aggregated Collection. v1 (2019). Last accessed: 2020-03-29, permalink: hdl.handle.net/102.100.100/137152? index=1.

2. Hemer, M., Trenham, C., Durrant, T. \& Greenslade, D. CAWCR Global wind-wave 21 st century climate projections. v1 (2015). Last accessed: 2020-03-29, DOI: doi.org/10.4225/08/55C991CC3F0E8.

3. Zuo, H., Balmaseda, M. A., Tietsche, S., Mogensen, K. \& Mayer, M. The ecmwf operational ensemble reanalysisanalysis system for ocean and sea ice: a description of the system and assessment. Ocean. Sci. 15, 779-808, DOI: 10.5194/os-15-779-2019 (2019).

4. Caldwell, P. C., Merrifield, M. A. \& Thompson, P. R. Sea level measured by tide gauges from global oceans — the Joint Archive for Sea Level holdings (NCEI Accession 0019568). Dataset. Version 5.5, NOAA National Centers for Environmental Information, (2015). DOI: 10.7289/V5V40S7W.

5. Burcharth, H. F., Hawkins, S. J., Zanuttigh, B. \& Lamberti, A. Design tools related to engineering. In Burcharth, H. F., Hawkins, S. J., Zanuttigh, B. \& Lamberti, A. (eds.) Environmental Design Guidelines for Low Crested Coastal Structures, 203 - 333, DOI: doi.org/10.1016/B978-008044951-7/50033-6 (Elsevier Science Ltd, Oxford, 2007).

6. David, C. G., Ballesteros, P. \& Schlurmann, T. Coastal Digital Elevation Models and Transects of the Reef Island Fuvahmulah, the Maldives [Dataset]. Zenodo DOI: 10.5281/zenodo.4304049 (2020). 